\title{
Otimização de uma campanha publicitária na rede de pesquisa do Google Ads utilizando Teoria da Decisão Bayesiana
}

\author{
Felipe Martins \\ DissERTAÇÃO APRESENTADA \\ $\mathrm{AO}$ \\ Instituto De MATEmÁtica e EstatísticA \\ DA \\ UniversidAdE DE SÃO PAULO \\ PARA \\ OBtençÃo DO Título \\ $\mathrm{DE}$ \\ MESTRE EM CIÊNCIAS \\ Programa: Estatística \\ Orientador: Prof. Dr. Luís Gustavo Esteves \\ Durante o desenvolvimento deste trabalho o autor recebeu auxílo \\ financeiro do CAPES
}

São Paulo, Julho de 2019 


\section{Otimização de uma campanha publicitária na rede de pesquisa do Google Ads utilizando Teoria da Decisão Bayesiana}

Esta versão da dissertação contém as correções e alterações sugeridas pela Comissão Julgadora durante a defesa da versão original do trabalho, realizada em 22/07/2019. Uma cópia da versão original está disponível no Instituto de Matemática e Estatística da Universidade de São Paulo.

Comissão Julgadora:

- Prof. Dr. Luis Gustavo Esteves (IME-USP)

- Profa.Dra. Verónica Andrea González-López (UNICAMP)

- Prof.Dr. Rafael Bassi Stern (UFSCar) 


\section{Agradecimentos}

Agradeço primeiramente a Deus, pelo dom da vida, por todas coisas boas, pelos desafios que me proporcionou e por ter colocados pessoas que foram verdadeiros anjos na minha vida, as quais, sem duvida nenhuma, eu não estaria aqui neste momento sem a ajuda e o apoio delas.

Gostaria de agradecer especialmente ao meu orientador Luís Gustavo Esteves. Ele foi um verdadeiro irmão, que na hora em que todos me deram as costas me acolheu e me ajudou nesta empreitada. Luís, eu serei eternamente grato a você, por tudo que você fez por mim, não existe preço nem nada que eu possa fazer para retribuir seu apoio, por isto, mais uma vez o meu verdadeiro e mais sincero agradecimento.

Agradeço especialmente ao Caio Tabanez, que foi mais que um irmão. No começo do curso, quando eu não tinha bolsa me acolheu na sua casa, sem me pedir nada em troca, sempre serei grato por tudo que você sempre fez por mim. Agradeço também a Carol, esposa do Caio por toda compreensão em que tive em sua casa, meus mais sinceros obrigado.

Gostaria de agradecer minha mãe por seu apoio, colo e ajuda financeira. Você é sem dúvida nenhuma o maior presente que Deus me concedeu. Meus mais sinceros agradecimentos, eu te amo. Gostaria de agradecer a minha avó, que foi uma segunda mãe que esteve ao meu lado em vários momentos, muito obrigado vó, eu te amo. Gostaria de agradecer a minhas tias e tios e a todos os meus primos por seus apoios e incentivos.

Gostaria de agradecer a todos os meus amigos que fiz no IME, entre eles destaco: Pedro, Andrés, Francimario, Cátia, Deyvid, Shu, Nogc, Nicholas, Rodrigo, Elisa, Hugo, Laís, Moisés, Marina, Sitso e Magno. Meu muito obrigado.

Gostaria de agradecer aos seguintes professores: Victor Fossaluza, Silvia Nagib, Florencia Leonardi, Gilberto Paula, Antonio Galves e Viviana Giampaoli. Eles foram essenciais ou pelo 
apoio, ou por compartilharem seus conhecimentos comigo.

Gostaria de agradecer aos meus irmãos pela ajuda em especial ao Romulo e Ivah por terem me hospedado em sua casa e também por terem cuidado de mim quando fiquei doente. Agradeço a Luciana e ao Rofram por terem me escutados e me darem todo apoio e incentivo que puderam me dar.

Agradeço ao meu pai pela ajuda e pelo conselho de amigo nos momentos difíceis. Muito obrigado por entrar na minha vida, foi ótimo lhe conhecer, o meu agradecimento especial. 


\section{Resumo}

MARTINS, F. Otimização de um campanha publicitaria na rede de pesquisa do Google Ads utilizando Teoria da Decisão Bayesiana. Dissertação Mestrado - Instituto de Matemática e Estatística, São Paulo, 2019.

A publicidade digital promove produtos e serviços através da internet e proporciona uma excelente segmentação de clientes, pois pode filtrar clientes por determinado interesse. Entre todas as empresas que vendem espaços publicitários na internet, a que mais se destaca por quantidade de anunciantes e usuários é o Google Ads. A plataforma de anúncios do Google proporciona ao anunciante uma quantidade enorme de configurações para os anúncios. Por exemplo, na rede de pesquisa, o anunciante pode criar vários anúncios para diversas palavraschave e produtos, pode escolher um lance diferente por palavra-chave, dispositivo, data, dia da semana e hora do dia.

Entretanto, otimizar uma campanha com várias configurações possíveis não é algo trivial, pois requer que o agente decisor pense em todas as configurações possíveis e nos riscos induzidos por cada combinação de escolhas. Tradicionalmente, as campanhas são avaliadas por duas métricas: O ROI (Return of Investiment) e a taxa de conversão, essas métricas são calculadas em função de estatísticas descritivas da campanha e por mais eficientes que essa abordagem possa ser, não levam em consideração os fator aleatórios na tomada de decisão.

O propósito desta dissertação é criar uma metodologia, que será fundamentada em teoria da decisão, para determinar a configuração ótima para uma campanha no Google Ads utilizando uma perspectiva bayesiana.

Keywords: Teoria da Decisão Bayesiana, Otimização no Google Ads e Publicidade Digital. 


\section{Abstract}

MARTINS, F. Optimization of Online Advertising Campaign on Google Ads Search Network Using Bayesian Decision Theory. Dissertation (masters) - Institute of Mathematics and Statistics, São Paulo, 2019.

Internet advertising is a way to promote products and services through internet. This kind of advertisement provides an excellent approach to segment possible clients, since they can be filtered acording to their interests. Among the various digital advertising platforms, the most used in terms of the number of users is the Google Ads. Traditionally, campaigns are mainly created based on two metrics: the ROI (Return On Investment) and the Conversion Rate. However, as efficient as these methods may be, they do not consider other unknown variables that may influence the choice of the campaign.

The purpose of this Dissertation is to create a probability-based methodology for determining optimal settings within the Ads tool using a Bayesian perspective.

Keywords: Bayesian Decision Theory, Google Ads Optimization and Internet Advertisement. 


\section{Sumário}

Lista de Abreviações $\quad$ xi

Lista de Figuras $\quad$ xiii

$\begin{array}{ll}\text { Lista de Tabelas } & \text { Xv }\end{array}$

1 Introdução $\quad 1$

1.1 Sobre este Trabalho . . . . . . . . . . . . . . . . . . . . . . . 1

1.2 Motivação . . . . . . . . . . . . . . . . . . . . . . . . 2

1.3 Organização Desta Dissertação . . . . . . . . . . . . . . . . . . . . 2

2 Publicidade e Google Ads $\quad 3$

2.1 Introdução . . . . . . . . . . . . . . . . . . . . . . . . . . 3

2.2 Propaganda, Marketing Digital . . . . . . . . . . . . . . 3

2.2.1 Mass Marketing . . . . . . . . . . . . . . . . . 5

2.2.2 Inbound Marketing . . . . . . . . . . . . . . . . 5

2.2.3 Definições Básicas em Marketing Digital . . . . . . . . . . . . . 5

2.2.4 Principais KPIs utilizados no Marketing Digital . . . . . . . . . . 7

2.3 Google Ads . . . . . . . . . . . . . . . . . . . . . . . 10

2.3.1 Rede de Pesquisa e Rede de Display . . . . . . . . . . . . . . . . . . . 10

2.3.2 Tipos de Anúncios . . . . . . . . . . . . . . . . . . . 11

2.3.3 Ads Targeting . . . . . . . . . . . . . . . . . . 11

2.3 .4 Índice de Qualidade . . . . . . . . . . . . . . . . . . 12

2.3.5 Ads Rank . . . . . . . . . . . . . . . . . . . 13

2.3.6 Avaliação de Campanhas no Google Ads . . . . . . . . . . . . . . . . 13

3 Teoria da Decisão Bayesiana e Otimização de Monte Carlo 17

3.1 Introdução . . . . . . . . . . . . . . . . . . . . . . . . 17

3.2 Probabilidade . . . . . . . . . . . . . . . . . . . 17

3.3 Inferência Bayesiana . . . . . . . . . . . . . . . . . . . . . . . . 19

3.3.1 Teorema de Bayes . . . . . . . . . . . . . . . . . . . . . 20

3.3.2 Procedimento Bayesiano e Estimação Bayesiana . . . . . . . . . . . . 21

3.4 Teoria da Decisão . . . . . . . . . . . . . . . . . . . . . . . . . . 23 
3.4.1 Utilidade. . . . . . . . . . . . . . . . . . . . . . 24

3.4 .2 Principio da Utilidade Esperada . . . . . . . . . . . . . . . . 25

3.4 .3 Risk Taker e Risk Averse . . . . . . . . . . . . . . . . . . . 26

3.5 Otimização de Monte Carlo por Exploração Estocástica . . . . . . . . . . . . 27

4 Decisão Ótima no Google Ads 29

4.1 Introdução . . . . . . . . . . . . . . . . . . . . . . . . 29

4.2 Espaço de Decisão . . . . . . . . . . . . . . . . . . . . . . . 29

4.2.1 Conjunto de configurações . . . . . . . . . . . . . . . . . . . . 29

4.2 .2 Elementos do Espaço de Decisão . . . . . . . . . . . . . . . . . . . . . 32

4.2.3 Tamanho do Espaço de Decisão . . . . . . . . . . . . . . . . . 33

4.3 Funil de Vendas . . . . . . . . . . . . . . . . . . . . . . . . . . . . . . . 34

4.3.1 Estrutura Probabilística do Funil de Conversão . . . . . . . . . . . . 36

4.4 Ganho e Custo por Impressão (GPI e CPI) . . . . . . . . . . . . . . . . . . . 39

4.5 Ganho e Gasto Esperado . . . . . . . . . . . . . . . . . . . . . . . . 40

4.6 Número Esperado de Impressões . . . . . . . . . . . . . . . . . . . . . . . . . 40

4.7 Obtendo o Lucro Esperado . . . . . . . . . . . . . . . . . . . . . . . 42

4.8 Restrição do Espaço de Decisão . . . . . . . . . . . . . . . . . . . . 43

4.9 A Existência de um $C P C M_{s}$ que maximiza o Lucro Esperado $s \ldots . . . . \quad 45$

4.9.1 Algoritmo para Encontrar o CPCM Máximo . . . . . . . . . . . . . . 47

4.9 .2 Obtendo a Solução Ótima . . . . . . . . . . . . . . . . . 47

5 Procedimento Bayesiano e Simulações $\quad 51$

5.1 Procedimento Bayesiano . . . . . . . . . . . . . . . . 51

5.1 .1 Elicitação de Prioris . . . . . . . . . . . . . . . . . 52

5.1 .2 Encontrando a Distribuição Posteriori . . . . . . . . . . . . . . 57

5.2 Simulações . . . . . . . . . . . . . . . . . . . . . . . . . . . . . 59

5.2 .1 Planejamento ......................... 60

5.2 .2 Metodologias ........................ 60

5.2 .3 Resultados . . . . . . . . . . . . . . . . . 61

$\begin{array}{lll}6 & \text { Conclusão } & 63\end{array}$

$\begin{array}{ll}\text { A Classes com priores Conjugadas } & 65\end{array}$

A.1 Priori Beta e amostras de Bernoullis . . . . . . . . . . . . . . . 65

A.2 Priori Gama e amostras de Poisson . . . . . . . . . . . . . . 65

A.3 Priori Pareto e amostras de Uniforme . . . . . . . . . . . . . . . . 65

A.4 Priori Gama e amostras de Exponencial . . . . . . . . . . . . . . . . . 66

A.5 Prioris Normais e Gama com amostras Normais . . . . . . . . . . . . . . . 66

A.6 Prioris Dirichilet com amostras Multinomiais . . . . . . . . . . . . . . 66 
B Otimização de MC para Calcula CPCM

Referências Bibliográficas 


\title{
Lista de Abreviações
}

\author{
API Interface de Programação e Aplicação (Application Programming Interface) \\ CPC Custo por Clique (Cost per click) \\ CPM Custo por Mil Impressões (Cost per Thousand Impressions) \\ CPA Custo por Aquisição (Cost per Acquisition) \\ CPL Custo por Lead (Cost per Lead) \\ CR Taxa de Conversão (Conversion Rate) \\ KW Palavra-Chave (keyword) \\ CTR Taxa de clique (Click Through Rate) \\ ROI Retorno sob o investimento (Return on Investiment) \\ ROAS Retorno sob o investimento publicitário (Return on Advertising Spend) \\ URL Universal Resource Locator \\ SERP Página de resultado de pesquisa (Search Engine Results Page) \\ KPI Indicadores chaves de performance (Key Performance Indicators) \\ PPC Pagamento por clique (Pay per Click)
}




\section{Lista de Figuras}

2.1 Search Engine Results Page-SERP . . . . . . . . . . . . . . 7

4.1 Funil de Vendas . . . . . . . . . . . . . . . . . . . . . . . . . . . 38

4.2 Investimento máximo por $\mathrm{CPCM} \ldots \ldots \ldots$

4.3 ROAS por CPCM . . . . . . . . . . . . . . . . . . 46

5.1 Distribuições a Priori de São Paulo . . . . . . . . . . . . . . . . . . 54

5.2 Distribuições a Priori de Caieiras . . . . . . . . . . . . . . . . . 55

5.3 Planejador de Palavras-Chave . . . . . . . . . . . . . . . . . . 57

5.4 Boxplot do Lucro das Campanhas . . . . . . . . . . . . . . . . . . 62

5.5 Boxplot do Lucro mais Sobra das Campanhas . . . . . . . . . . . . . . . . 62

B.1 Lógica do programa . . . . . . . . . . . . . . . . . . . . . . . . . 68 


\section{Lista de Tabelas}

2.1 Tipo e locais dos anúncios nas redes do Google . . . . . . . . . . . . . . . . 11

2.2 Campanha Hipotética no Google Ads . . . . . . . . . . . . . . . . . . . . 14

2.3 Campanha Hipotética no Google Ads sem a KW "B" . . . . . . . . . . . . . 14

3.1 Risco de Sinistro . . . . . . . . . . . . . . . . . . 26

4.1 Quantidade de anúncios e Página de Destino segundo as configurações . . . . 33

4.2 Distribuição de probabilidade do $C P I_{s_{a d_{i}}}$ e do $G P I_{s_{a d_{i} l d_{j}}} \mid C R_{s_{a_{i} l d_{j}}} \ldots \ldots . . \quad 39$

4.3 Alocando o Budget na campanha . . . . . . . . . . . . . . . 49

5.1 Quantidade média de buscas por palavra chave em algumas cidades paulista 53

5.2 Priori por palavra chave e cidade . . . . . . . . . . . . . . 54

5.3 Demostrativo da Campanha Utilizando Teoria da Decisão . . . . . . . . . . . 61

5.4 Demostrativo da Campanha Utilizando Método Tradicional . . . . . . . . . . 61

5.5 Comparativo do ROAS e CPA entre a metodologia proposta e a tradicional . 62 


\section{Capítulo 1}

\section{Introdução}

\subsection{Sobre este Trabalho}

Antes da internet, as empresas divulgavam seus produtos através de jornais, revistas, panfletos, televisão e rádio. Os anúncios eram visualizados por uma grande quantidade de pessoas, entretanto, o público-alvo atingido representava uma proporção muito pequena dos que visualizavam a propaganda. Com os avanços da internet, as empresas puderam encontrar diretamente seu público de interesse. Além disso, os consumidores ficaram mais próximos das empresas, pois assim podem analisar um produto antes de comprar, ver avaliações de outros consumidores e interagir com a marca.

De modo geral, o objetivo principal de uma boa campanha publicitária é aumentar o lucro, levando em consideração uma quantidade limitada de recursos disponíveis. Por esta perspectiva, encontrar uma estratégia que otimize recursos para um campanha online é extremamente relevante.

Em busca de resolver este problema alguns trabalhos na literatura por exemplo, Duijndam (2011) tenta resolver o problema utilizando uma variação do problema das mochilas e Muthukrishnan et al. (2010) usa um modelo estocástico. Entretanto, não foi encontrado trabalho na literatura que proponha uma solução para este problema através da Teoria da Decisão Bayesiana. Graepel et al. (2010) usa uma abordagem Bayesiana apenas para fazer previsões da taxa de cliques (click through rate - CTR), mas não para maximizar o lucro. Esta dissertação foca resolver o problema de alocação ótimo de recursos sob a perspectiva da Teoria da Decisão Bayesiana. 


\subsection{Motivação}

Os métodos atuais de análise utilizados para tomar decisão e otimizar campanhas no Google, ainda eficientes, não consideram fatores aleatórios que influenciam diretamente nas campanhas, fatores tais como a incerteza sobre a quantidade de buscas, sazonalidade, probabilidade de cliques, entre outros.

Além disso, a análise tradicional do Google Ads examina as campanhas como se a quantidade de buscas por cada palavra-chave fosse ilimitada. Entretanto, sabe-se que por maior que seja a quantidade de buscas, ela é finita. O que consequentemente faz com que quantidades diferentes de investimentos gerem resultados diferentes. Basicamente, no método tradicional as otimizações são tomadas em função de certos KPI (Key Performance Indicators) que são algumas estatísticas de performance da campanha. Desse modo, estudaremos um processo de otimização de uma campanha publicitária baseado em Teoria da Decisão que contemple esses aspectos negligenciados sob o método tradicional.

\subsection{Organização Desta Dissertação}

Esta dissertação está dividida da seguinte forma: este primeiro capítulo faz uma breve introdução sobre o tema que este trabalho desenvolve, o segundo capitulo apresenta o funcionamento das campanhas do Google Ads e apresenta os principais conceitos utilizados na publicidade on-line; o terceiro capitulo faz o embasamento teórico da solução proposta e apresenta as principais técnicas utilizadas neste trabalho; o quarto capitulo aplica os conceitos da Teoria da Decisão Bayesiana para escolher a configuração ótima para uma campanha do Google Ads; o quinto capítulo mostra como foi realizado o procedimento Bayesiano para encontrar as distribuições a posteriori de parâmetros do modelo, aqui é apresentado o método de elicitação de prioris informativas e também apresenta o resultado de umas simulações feitas comparando o método desenvolvido neste trabalho com o que é mais utilizados pelos usuários do Google Ads; o sexto capítulo contem as conclusões finais deste trabalho e faz recomendações para trabalhos futuros. 


\section{Capítulo 2}

\section{Publicidade e Google Ads}

\subsection{Introdução}

Esse capitulo apresenta alguns conceitos sobre marketing digital e descreve como funciona uma campanha no Google Ads.

\subsection{Propaganda, Marketing Digital}

Para detalhar como o Google Ads funciona, é importante mostrar algumas estratégias utilizadas no marketing. Mas, para entender como elas ocorrem, é necessário entender um processo de vendas.

O objetivo de conhecer o processo de vendas é tentar entender o comportamento do consumidor e os estágios que ele percorre até adquirir um produto com o intuito de entender como ele vai reagir quando for exposto a publicidade em cada fase do processo de compra.

Antes de mais nada, é importante ressaltar que ninguem compra um produto em si, mas o beneficio que produto proporciona ao comprador. Por exemplo, quando uma pessoa tem um vazamento na sua casa e contrata um encanador, ela não estará comprando canos novos para sua casa, mas sim uma casa seca, arrumada e limpa.

Portanto, uma pessoa ao adquirir um produto tenta resolver um problema pessoal, ou satisfazer um desejo pessoal. Entretanto, nem sempre ela está ciente dessa necessidade e, dependendo do grau de ciência, ela estará em um momento de compra diferente. Para entender exatamente porque as pessoas compram KOTLER (2017) detalha em seu livro MARKE- 
TING 4.0 - Moving from Traditional to Digital no qual ele propõe metodologias que ajudam a montar campanhas publicitárias eficientes nesta era digital.

Para tentar exemplificar como o processo de vendas funciona, vamos supor que uma pessoa tenha dor nas costas ao acordar, mas que até agora ela não priorizou tal desconforto, pois, assim que acorda, por mais incômoda que seja a dor, em poucos minutos a dor passa. Neste caso, esta pessoa se encontra em estágio inicial de compra, pois ela possui um problema mas talvez ainda não o incomode suficientemente para que ela procure alguma solução.

Com o tempo, essas dores passam a incomodar mais e o dia todo em vez de alguns instantes. Neste caso, o individuo já percebeu o seu problema e está em buscas de possíveis soluções do mesmo, o que o leva a pesquisar na internet, conversar com amigos e assim por diante em busca de possíveis formas de aliviar as dores. Neste caso, este individuo está em outro momento de compra, muito mais propenso do que o anterior a realizar uma compra para resolver o seu problema.

Esta mesma pessoa que agora sofre com dores terríveis nas costas descobriu que o que causava as dores era que seu colchão estava muito velho e resolve comprar um colchão novo, com isto, ela vai para a última fase da compra o que KOTLER 2017 chama de ação.

De forma geral, uma pessoa só vai comprar algo somente quando achar que o valor do produto é maior que o preço dele. O valor representa de forma subjetiva a percepção que o consumidor possui do quanto o produto vale, gerando beneficio e satisfação, enquanto que o preço é o que é cobrado pelo produto. No exemplo acima, uma cama nova para alguém que tenha dores crônicas nas costas decorrentes do uso de um colchão velho tem um valor muito maior do que para quem tem dores ocasionais mesmo que ambas vejam o mesmo preço na etiqueta de venda.

O valor nada mais é do que a utilidade (satisfação) que aquele produto vai trazer para o individuo, e o preço é quanto se paga pelo produto. Sob esta perspectiva Adolpho 2016 evidencia que para cada momento de compra é necessário gerar valor suficiente para que um usuário esteja disposto a pagar um determinado preço para realizar uma compra.

Assim, é de grande importância para uma empresa saber identificar o momento de compra de um cliente de modo a lhe direcionar propagandas persuasivas que gerem valor para cada etapa da venda. Sob este foco as próximas seções apresentam algumas dessas estratégias no 
marketing.

\subsubsection{Mass Marketing}

O principal foco do marketing de massa(Mass Marketing) é fazer propaganda em canais de grandes circulação, ou tiragem, como jornais, panfletos, revistas, televisão e rádio. A comunicação é realizada em apenas uma direção, ou seja, das empresas para os consumidores, e os consumidores não podem interagir ou responder à propaganda. O objetivo principal é apresentar o produto para a maior quantidade de pessoas possíveis para encontrar clientes que já estão em um momento final de compra.

\subsubsection{Inbound Marketing}

O foco principal do inbound marketing é segmentar o cliente com base em seus interesses e focar num nicho específico. Aqui, atua-se com clientes em diferentes estágios da venda. De acordo com (Halligan et al, 2009) e (Patrutiu Baltes 2016), inbound marketing é inspirado na natureza. O objetivo é atrair os clientes do mesmo modo que a flor atrai os insetos para espalhar o seu pólen. Busca-se atrair o cliente que já possui alguma característica específica, ou seja, pertencente a um público-alvo específico e que possa ou não já ter interesse no produto. Portanto, pode-se captar clientes em momentos de compra diferente; desde aqueles que não sabem que possuem um problema até quem já está no momento final de compra.

\subsubsection{Definições Básicas em Marketing Digital}

Alguns conceitos básicos em marketing digital que ajudarão na compreensão e desenvolvimento desse trabalho são apresentados a seguir mas também podem ser encontrados no livro Os 8 Ps do Marketing Digital de Adolpho 2016.

\section{E-commerce}

E-commerce é uma loja de vendas on-line.

\section{Prospect}

Qualquer possível novo cliente para um empresa, produto ou serviço. Vale lembrar que prospect seria alguém que pertence ao meu público-alvo mas que eu ainda não possuo o 
contato dele, tanto que na área comercial é comum dizer que deve-se propectar clientes no sentido que deve-se captar clientes.

\section{Lead}

Lead é quando se obtêm os dados de um Prospect. Ou seja, é quando se pega algum contato com o cliente podendo-se abrir um canal de comunicação com ele. Por exemplo, quando um usuário se cadastra em uma lista de e-mail ele deixa de ser um propect e se transforma em um lead.

\section{Buyer}

Quando um Propect ou Lead faz uma compra, ele vira um comprador (Buyer).

\section{Produto Front-end e Back-end}

O produto Front-end é um produto de entrada, ou seja, um produto mais barato, ou a preço de custo, com o objetivo de transformar um prospect em buyer, preparando para vender o produto Back-end que pode ser considerado o produto objetivo.

A ideia central de se trabalhar com produto front-end é fundamentada no Inbound Marketing: o objetivo é criar relacionamento com cliente, agregando valor para a marca, fazendo com que seja muito mais fácil vender o produto back-end.

\section{Budget}

O Budget representa a verba de marketing direcionada às campanhas, ou seja, é o valor investido em publicidade.

\section{Impressão}

O termo impressão se originou com a mídia impressa e representava a quantidade de revistas, jornais e panfletos impressos. Na mídia digital, impressão é a quantidade de pessoas que visualizam o anúncio ou a página do anúncio.

\section{Conversão}

Conversão representa uma meta ou um objetivo de um web-site. Já para um e-commerce, conversão é uma venda. Assim, em um site de uma clínica, conversão é o agendamento de uma consulta ou a compra de um tratamento. Pode-se ter várias conversões no mesmo site, por exemplo, cadastrar-se em uma lista de e-mails, clicar em um botão comprar, finalizar uma compra ou compartilhar conteúdo.

\section{SERP}


A sigla SERP em inglês significa Search Engine Results Page e representa as páginas que exibem os resultados de uma busca na internet. Por exemplo, quando um usuário digita uma palavra-chave no google, a página com os resultados da pesquisa é a SERP. A Figura 2.1 mostra a SERP obtida pesquisando-se "SERP" no google.

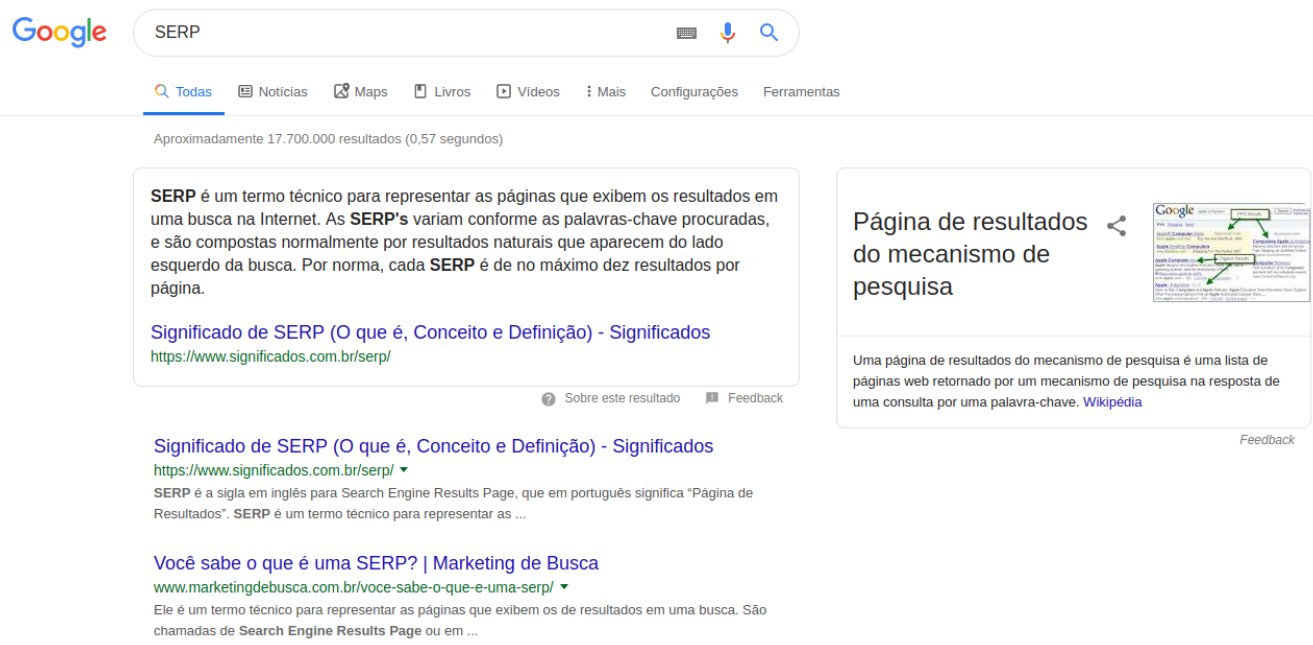

Figura 2.1: Search Engine Results Page - SERP

\section{Remarketing}

Remarketing é um tipo de propaganda direcionada a um usuário que já visitou um determinado web-site. O objetivo deste tipo de propaganda é lembrar o usuário, constantemente, enquanto ele navega na internet de um determinado interesse que ele possua, provavelmente, proveniente de alguma busca anterior e com isto melhorar a conversão.

\subsubsection{Principais KPIs utilizados no Marketing Digital}

Key Performance Indicators (KPI) são algumas estatísticas que são comumente chamadas de métricas em marketing digital e servem para descrever certos eventos no marketing digital. Para maiores detalhes sobre essas métricas consultar Adolpho (2016).

\section{Taxa de Conversão}

Taxa de conversão $(C R)$ é definida como a razão entre a quantidade de conversões pela quantidade total de pessoas que entraram no site. Neste trabalho, como nosso interesse é avaliar uma campanha do Google Ads, vamos considerar que o total de pessoas que entram no site é correspondente à quantidade de cliques. Assim: 


$$
\mathrm{CR}=\frac{\text { Número de Conversões }}{\text { Número de Cliques }}
$$

A grosso modo, pode-se imaginar conversão como o "sucesso" do site e a taxa de conversão como a probabilidade que cada usuário que entre no website converta.

\section{Click Through Rate (CTR)}

$C T R$ é a razão entre a quantidade de Cliques recebidas por um anúncio e o total de impressões. O CTR também pode ser expresso em porcentagem.

$$
\mathrm{CTR}=\frac{\text { Cliques }}{\text { Impressões }}
$$

Do mesmo modo que a taxa de conversão, o CTR pode ser visto como a probabilidade de um anúncio receber um clique por algum usuário.

\section{Return of Investment (ROI)}

O ROI é a razão entro o lucro dividido pelo custo total. No cálculo do ROI, entram todos os custos, incluindo impostos, alugueis, transporte, etc. Resumidamente:

$$
\text { ROI }=\frac{\text { Ganhos }- \text { Custos }}{\text { Custos }}=\frac{\text { Lucro Liquido }}{\text { Custo Total }}
$$

Por exemplo, se uma empresa vende um produto por $\mathrm{R} \$ 200,00$ reais e o custo total é de $\mathrm{R} \$ 100$, então o ROI será de 1 . Ou seja, a cada 1 real investido, é obtido um lucro de 1 Real. Assim pode-se dizer que houve um retorno sobre investimento de 100\%. Para maiores detalhes sobre o ROI, pode-se pesquisar em Levin (2004) e GOOGLE (b).

\section{Return on Advertising Spend (ROAS)}

O ROAS é um índice similar ao ROI para analisar gastos exclusivamente com publicidade, ele mede o retorno vindo especificamente da publicidade. Desta forma, o ROAS ajuda a empresa a descobrir se uma campanha está dando lucro ou não. O ROAS pode ser calculado da seguinte forma:

$$
\text { ROAS }=\frac{\text { Ganhos }- \text { Investimento em Publicidade }}{\text { Investimento em Publicidade }}
$$

Por exemplo, se uma empresa investir $\mathrm{R} \$ 50,00$ em uma campanha no Google Ads e 
obtiver 100 reais de lucro, então o ROAS será de 1 . Portanto, cada $\mathrm{R} \$ 1,00$ real investido no Google Ads, trará um lucro de $\mathrm{R} \$ 1,00$ real.

O gasto em campanhas é equivalente ao investimento em publicidade, logo pode-se reescrever o ROAS da seguinte forma:

$$
\text { ROAS }=\frac{\text { Ganhos }- \text { Gastos em campanhas }}{\text { Gastos em campanhas }}
$$

\section{CPC}

A sigla $C P C$ em inglês significa " cost per click"e representa o custo pago por clique pelo anunciante. Ele pode ser calculado da seguinte forma:

$$
\mathrm{CPC}=\frac{\text { Gastos }}{\text { Número de Cliques }}
$$

Por exemplo, se uma campanha teve 174 cliques gastando $\mathrm{R} \$ 87,00$ o $C P C$ foi de $\mathrm{R} \$$ 0,50, ou seja, em média cada clique custou cinquenta centavos. O CPC é uma métrica muito importante pois geralmente é os anúncios são pagos quando há cliques.

\section{CPL}

A sigla $C P L$ em inglês significa "cost per lead"e representa o custo pago por lead. Ele pode ser calculado da seguinte forma:

$$
\mathrm{CPL}=\frac{\text { Gastos }}{\text { Número de Leads }}
$$

Por exemplo, se uma campanha teve 87 leads gastando $\mathrm{R} \$ 87,00$ o $C P L$ foi de $\mathrm{R} \$ 1,00$, ou seja, em média cada lead custou um real.

\section{CPA}

A sigla CPA em inglês significa "Cost per acquisition"e representa o custo pago por conversão. Ele pode ser calculado da seguinte forma:

$$
\mathrm{CPA}=\frac{\text { Gastos }}{\text { Número de Conversões }}
$$

Note que também pode-se calcular o $C P A$ pela seguinte formula: 


$$
\mathrm{CPA}=\frac{\mathrm{CPC}}{\mathrm{CR}}=\frac{\frac{\text { Gastos }}{\text { Número de Cliques }}}{\frac{\text { Número de Conversões }}{\text { Número de Cliques }}}=\frac{\text { Gastos }}{\text { Número de Conversões }}
$$

Por exemplo, se uma campanha teve 5 conversões gastando $\mathrm{R} \$ 87,00$ o $C P A$ foi de $\mathrm{R} \$$ 17,40, ou seja, em média, cada conversão custou $\mathrm{R} \$ 17,40$.

\subsection{Google Ads}

Google Ads (GOOGLE (a)) é a plataforma de anúncio do Google, onde um anunciante pode criar e configurar suas campanhas. O Google Ads é fundamentado no Inbound Marketing, pois todas as propagandas são direcionadas a uma audiência específica com o objetivo de atraí-la. Um usuário ao navegar pela internet pode visualizar os anúncios quando:

- Faz uma pesquisa no site do Google e visualiza alguns anúncios relacionados com a palavra-chave que digitou.

- Quando navega na internet e visualiza anúncios de sites que já visitou ou com conteúdo relacionado com o site que está navegando.

Basicamente um usuário pode visualizar os anúncios enquanto navega na internet em sites parceiros ou diretamente na SERP do Google. O grande benefício deste tipo de publicidade é a capacidade de personalizar a propaganda para cada tipo de busca e momento de compra diferente, filtrando por interesses. Por exemplo, se um usuário digita "Qual é o melhor tipo de tênis para corrida"na SERP do google, um anúncio pode direcioná-lo para um site explicando sobre quais tipos de tênis são melhores para corridas e colocar os links para produtos específicos em sites de compra, enquanto que para um usuário que digita "Tênis da marca X de corrida modelo YZ preço", o anúncio direciona o usuário para uma página de venda do modelo YZ.

\subsubsection{Rede de Pesquisa e Rede de Display}

A rede do google é dividida em duas partes, a rede de pesquisa e a rede de display. Na rede de pesquisa, o anúncio pode ser exibido na página de resultados de pesquisa do google 
(no topo da página ou no rodapé) e em sites parceiros que exibem resultados de pesquisa.

A rede de display alcança as pessoas enquanto elas estão navegando na internet, assistindo a um video no youtube, ou lendo um e-mail no gmail. Os sites parceiros do google se cadastram no programa Google AdSence e recebem uma parcela do valor que os anunciantes pagam pelos anúncios.

\subsubsection{Tipos de Anúncios}

Dependendo da rede de pesquisa, há diferentes formatos de anúncio e locais de exibição. Abaixo, na Tabela 2.1, temos os formatos dos anúncios e o locais dos anúncios em cada rede do Google.

\begin{tabular}{l|c|c}
\hline Rede & Local de Exibição & Tipo de Anúncio \\
\hline \multirow{4}{*}{ Pesquisa } & SERP & Texto \\
\cline { 2 - 3 } & Google Play & Texto \\
\cline { 2 - 3 } & Google Shopping & Texto \\
\cline { 2 - 3 } & Google Maps & Texto \\
\hline \multirow{4}{*}{ Display } & Sites Parceiros & Imagem \\
\cline { 2 - 3 } & & Flash \\
\cline { 2 - 3 } & Youtube & Videos \\
\cline { 2 - 3 } & Gmail & Formulários \\
\cline { 2 - 3 } & & Vídeos \\
\cline { 2 - 3 } & & Imagens \\
\hline
\end{tabular}

Tabela 2.1: Tipo e locais dos anúncios nas redes do Google

Na tabela 2.1, observa-se que todos os anúncios da rede de pesquisa são no formato texto. Entretanto, este trabalho abordará apenas o problema de otimização de resultados da rede de pesquisa das campanhas exibidas na SERP. Portando, não serão abordados anúncios tipo texto em outros locais de exibição e tampouco outros tipos de anúncios.

\subsubsection{Ads Targeting}

Para configurar a exibição dos anúncios, um anunciante seleciona as palavras-chave que ativam os seus anúncios. Portanto, quando uma pessoa faz uma busca no google, o anúncio estará elegível a aparecer apenas para aquelas palavras-chave.

A ideia central de se escolher palavras para ativar um anúncio é tentar descobrir o interesse real do usuário ao fazer a busca, inclusive escolher palavras-chave diferentes para 
cada momento da compra que ele se encontra. Por exemplo, se um usuários pesquisa por "tênis da marca X de corrida masculino preço", ele está mais propenso a comprar do que alguém que pesquisa por "tênis para correr".

\subsection{4 Índice de Qualidade}

As pessoas possuem tanta credibilidade no google que quando estão doentes costumam primeiro pesquisar na internet do que procurar um médico, apesar disto, as pessoas se esquecem que por trás da página de pesquisa (SERP) há um algoritmo que apresenta os resultados. Para criar e manter tal credibilidade o Google Ads é construído utilizando os princípios do Inbound Marketing que, em função disto, considera a experiência do usuário muito mais importante do que vender espaços publicitários.

Com o objetivo de fazer com que os anúncios sejam mais relevantes para seus usuários, e também para garantir que esses usuários encontrem o que estão procurando e que assim possuam ter boa experiência ao utilizar o Google, o Google Ads utiliza o "Índice de Qualidade", que penaliza anunciantes com baixa qualidade fazendo com que paguem mais caro por clique e até mesmo bloqueando totalmente a exibição dos anúncios, e por outro lado beneficiando anunciantes com alta qualidade fazendo com que paguem menos por clique e consequentemente possuam campanhas mais lucrativas.

Basicamente, quanto maior é o índice de qualidade, mais relevante é o anúncio para um usuário, pois para construir o índice de qualidade, o Google utiliza os seguintes critérios (ver mais em GOOGLE (c)):

- CTR.

- Página de destino do anúncio.

- Relevância do anúncio para a palavra-chave.

Um dos principais motivos para o Google considerar o CTR é que como a propaganda é paga por clique, então quanto mais cliques o anúncio possui mais rentável ele será. Além disso, CTR alto significa que o usuário também achou o anúncio relevante. 
A página destino é importante pois considera a experiência do usuário ao navegar: por exemplo, o carregamento lento de uma página, ou a existência de alguma falha de segurança para o usuário seria considerado uma falha muito grave para o Google, pois, a satisfação do usuário com as indicações do google diminuiria.

A relevância do anúncio com a palavra-chave verifica se o usuário achou aquilo que estava procurando, pois um usuário ficaria bastante frustrado se clicasse em um anúncio sobre carros e fosse direcionado para uma página que vende roupas.

\subsubsection{Ads Rank}

A SERP possui uma quantidade fixa de locais que podem receber os anúncios. Para determinar qual anunciante vai em cada posição é realizado um leilão que vai classificar os anunciantes utilizando um algoritmo de ranqueamento e classificação dos anúncios.

O que leiloado é a posição do anúncio, entretanto o anunciante não é tarifado quando seu anúncio é exibido e somente quando há um clique. Na verdade, há outras formas de cobrança no google ads sem ser necessariamente por cliques, tais métodos de pagamentos não serão levados em consideração neste trabalho.

O Ads Rank é o algoritmo de ranqueamento e classificação dos anúncios no Google Ads. Ele utiliza o lance máximo por palavra-chave e o índice de qualidade como parâmetros para classificar os anúncios. Quando o anunciante cria uma campanha, automaticamente o Ads Rank classifica o anúncio e, dependendo da classificação, o anúncio pode ou não aparecer e, quanto melhor é a classificação desse anúncio, melhores são as posições ocupadas pelo anúncio na página de destino e, consequentemente, terá um $C T R$ maior.

\subsubsection{Avaliação de Campanhas no Google Ads}

Para avaliar uma campanha publicitária on-line, os anunciantes geralmente utilizam duas métricas, o $R O A S$ e o $C P A$, que representam o retorno financeiro sobre o anúncio e o custo por aquisição, respectivamente. O $R O A S$ e o $C P A$ que foram descritos na seção 2.2.3.

Consideremos, por exemplo a seguinte campanha publicitária hipotética. Uma empresa vende um produto com $\mathrm{R} \$ 10,00$ de lucro por unidade. A empresa anuncia no Google Ads e 
seleciona 4 palavras-chave $(\mathrm{KW})$ : "A", "B", "C"e "D". O resumo da campanha da empresa está na Tabela 2.2. Analisando a campanha, observa-se que no geral houve 3849 impressões, 117 cliques, 13 conversões (vendas), gastando um total de $\mathrm{R} \$ 85,87$ reais, com lucro bruto de 130,00 reais. Nesse caso, observa-se um ROAS de 0,51 e um CPA de R $\$$ 6,61. Portanto, a campanha é lucrativa pois o CPA é menor que o lucro unitário (R\$10,00) e o ROAS é positivo. Então, é investido $\mathrm{R} \$ 6,61$ em publicidade para se fazer uma venda e a cada 1 real investido ganha-se um lucro de $\mathrm{R} \$ 0,51$. O lucro liquido total foi de $\mathrm{R} \$ 44,13$ reais.

\begin{tabular}{l|cccccccccc}
\hline KW & Impressões & Cliques & Conversões & CTR & CR & CPC & Gasto & Lucro & ROAS & CPA \\
\hline "A" & 500 & 25 & 2 & 0,05 & 0,08 & 0,48 & 12,00 & 20,00 & 0,67 & 6,00 \\
"B" & 3003 & 135 & 3 & 0,04 & 0,02 & 0,23 & 31,05 & 30,00 & $-0,03$ & 10,35 \\
"C" & 261 & 12 & 5 & 0,05 & 0,42 & 2,01 & 24,12 & 50,00 & 1,07 & 4,82 \\
"D" & 85 & 5 & 3 & 0,06 & 0,60 & 3,74 & 18,70 & 30,00 & 0,60 & 6,23 \\
\hline Total & 3849 & 177 & 13 & 0,05 & 0,07 & 0,49 & 85,87 & 130,00 & 0,51 & 6,61 \\
\hline
\end{tabular}

Tabela 2.2: Campanha Hipotética no Google Ads

Entretanto, mesmo com a campanha sendo lucrativa, a palavra chave "B" possui um ROAS negativo e um CPA $(10,35)$ maior que o lucro unitário $(\mathrm{R} \$ 10,00)$, fazendo com que ela gere um prejuízo de $\mathrm{R} \$ 0,35$ a cada conversão, ou seja, a cada 1 Real investido na KW "B"tem-se um prejuízo de $\mathrm{R} \$ 0,03$. Uma forma de melhorar a campanha nesse caso é diminuir o lance por clique desta palavra-chave ou até mesmo removê-la. Nota-se que a palavra-chave "B" é a que possui o menor CPC. Entretanto, é a que possui a menor taxa de conversão, evidenciando provavelmente, que um usuário que pesquisa por esta palavra-chave ainda não está em um momento de compra tão favorável, ou que talvez essa palavra-chave não esteja muito relacionada com o público-alvo. Para analisar esta campanha sem a palavra chave "B", considere a Tabela 2.3.

\begin{tabular}{l|cccccccccc}
\hline KW & Impressões & Cliques & Conversões & CTR & CR & CPC & Gasto & Lucro & ROAS & CPA \\
\hline "A" & 500 & 25 & 2 & 0,05 & 0,08 & 0,48 & 12,00 & 20,00 & 0,67 & 6,00 \\
"C" & 261 & 12 & 5 & 0,05 & 0,42 & 2,01 & 24,12 & 50,00 & 1,07 & 4,82 \\
"D" & 85 & 5 & 3 & 0,06 & 0,60 & 3,74 & 18,70 & 30,00 & 0,60 & 6,23 \\
\hline Total & 846 & 42 & 10 & 0,05 & 0,24 & 1,31 & 54,82 & 100,00 & 0,82 & 5,48 \\
\hline
\end{tabular}

Tabela 2.3: Campanha Hipotética no Google Ads sem a $K W$ "B"

Sem a palavra chave "B", a campanha fica mais lucrativa, pois o lucro final é de $\mathrm{R} \$ 45,18$, o que é evidenciado por um CPA de $\mathrm{R} \$ 5,48$, ou seja, menor que $\mathrm{R} \$ 6,61$ da campanha original incluindo "B". Logo, ficou mais rentável, pois se gasta menos para se obter uma conversão 
e isto é confirmado pelo ROAS de 0,82: a cada 1 real investido, se tem um lucro de $\mathrm{R} \$ 0,82$ em vez de $\mathrm{R} \$ 0,51$ como na campanha com a KW "B".

Esta é a metodologia que é geralmente utilizada para analisar e otimizar uma campanha no Google Ads. Evidentemente, há várias variáveis adicionais utilizadas pelo mercado, como correspondência de palavra-chave, dia da semana, horário de exibição do anúncio, dispositivo dos usuários (pc, smartfones ou tablet), cidade e região onde é exibido o anúncio, dentre outras. Entretanto, as campanhas são geralmente analisadas através dessas métricas, ROAS e CPA. Embora úteis para comparação entre campanhas publicitárias, tais avaliações não constituem um procedimento formal para a obtenção da configuração ótima para uma campanha publicitária e sim um solução heurística para melhorar uma campanha. Além disso, tais avaliações não contemplam elementos incertos inerentes a tal problema de decisão. Este trabalho busca contribuir para esse problema de determinação da configuração ótima de uma campanha sob o olhar da Teoria da Decisão Bayesiana. 
PUBLICIDADE E GOOGLE $A D S$ 


\section{Capítulo 3}

\section{Teoria da Decisão Bayesiana e Otimização de Monte Carlo}

\subsection{Introdução}

Este capítulo apresenta a teoria na qual é baseada a otimização de uma campanha do Google Ads desenvolvida nesse trabalho. Inicialmente, será apresentado o conceito de probabilidade que é fundamental para lidar com situações de incerteza. Em seguida, será explicado como tratar essa incerteza através da Inferência Bayesiana, evidenciando o Teorema de Bayes e o procedimento bayesiano. Será apresentada também a Teoria da Decisão Bayesiana que formaliza a tomada de decisão racional através do princípio da utilidade esperada. Finalmente, será apresentada uma técnica que será utilizada nesse trabalho para obter o máximo de uma função.

\subsection{Probabilidade}

O termo probabilidade possui várias interpretações no dia a dia. Ele é utilizado geralmente em situações de pesquisas eleitorais, estudos clínicos ou para descrever preferencias dos consumidores, mas tudo de maneira informal.

O que se percebe é que embora muito utilizada, o domínio sobre a noção de probabilidade é bastante desconhecido. É comum as pessoas imaginarem que um evento com probabilidade 0,00001 nunca vai acontecer. Entretanto, a não ser que o evento possua probabilidade zero, ele pode ocorrer. Por exemplo, antes da copa 2014 de futebol nunca se imaginou que seria 
possível que a seleção brasileira de futebol perderia de 7 a 1 em uma copa do mundo, ainda mais jogando no Brasil. Mas, por mais improvável que seja, isto aconteceu.

Interpretações sobre probabilidade não estão restritas somente ao dia a dia, mas também estão presentes na área acadêmica. Probabilidade é um conceito matemático. Entretanto, é natural que as pessoas o interpretem de forma diferente. Entre as diversas interpretações de probabilidade, podemos citar as interpretações clássica, frequentista e subjetiva.

A interpretação clássica de probabilidade nasceu com o estudo de jogos de azar como cartas e dados. A versão clássica supõe que todos os eventos simples são equiprováveis. Assim, por exemplo, no lançamento de uma moeda, a chance de se obter cara é a mesma de se obter coroa e a probabilidade de um evento era calculada pela razão dos casos favoráveis ao evento sobre casos totais. O principal problema desta interpretação é que ela é ineficaz para estudar a grande maioria dos eventos do dia a dia nos quais não é possível supor equiprobabilidade dos eventos simples, como no caso de uma pessoa ter ou não uma doença.

A interpretação frequentista considera a probabilidade de um evento como o limite da frequência relativa com que tal evento ocorre sob as mesmas condições. Assim, a probabilidade de se obter cara de uma moeda é o limite da frequência relativa que se obtêm da razão entre o número de caras observadas e total de lançamentos da moeda quando se lança infinitas vezes a mesma moeda sob as mesmas condições. Entretanto, surgem alguns questionamentos sobre essa interpretação, como, por exemplo, no caso da moeda, nos perguntamos quantas vezes devemos jogar a moeda de modo a calcular tal limite da frequência relativa, ou o que seriam as "mesmas condições"do lançamento da moeda.

A interpretação subjetiva defende que probabilidade de um evento representa a crença que uma pessoa possui sobre determinado evento ocorrer. Portanto, a probabilidade não existe no mundo real, ela representa a incerteza do ser humano em algo ocorrer ou não, e por se tratar de algo subjetivo é natural supor que pessoas diferentes possuam ideias diferentes sobre um evento e atribuam probabilidades diferentes sobre determinado evento. Por exemplo, um individuo lança uma moeda e observa cara. Logo, para ele, a probabilidade de ter ocorrido cara é 1 (ele tem certeza da ocorrência de coroa); entretanto, outro indivíduo que não viu o resultado do lançamento atribuíra, possivelmente, outra probabilidade de ter ocorrido cara no lançamento da moeda. Mais detalhes em Understanding Uncertainty 
(Lindley, 2006) e Making Decisions (Lindley, 1991).

\subsection{Inferência Bayesiana}

Há duas formas de pensamento sobre inferência estatística que, de certo modo, são concorrentes: A inferência frequentista considera probabilidade de um evento como o limite tendendo ao infinito da frequência relativa da ocorrência de determinado evento quando se realiza um experimento sob as mesmas condições indefinidamente. Aqui, toda a incerteza é proveniente dos dados e não é possível utilizar a experiência de um especialista para fins inferenciais sobre um parâmetro. Por outro lado, na inferência Bayesiana considera-se probabilidade uma medida subjetiva para descrever incerteza e pode-se combinar a experiência do especialista com as informações resultantes do dados. Na qual, a informação proveniente do especialista é descrita através da distribuição a priori que é combinada com a informação proveniente dos dados através da verossimilhança (distribuição dos dados) que, por fim, através do Teorema de Bayes, essa combinação atualiza a incerteza através da distribuição posteriori.

O principal motivo pelo qual será considerada a abordagem Bayesiana para resolver o problema proposto é que no marketing digital há várias fontes de informações que podem ser incorporadas à tomada de decisão, sugerindo uma distribuição a priori para quantidades relevantes do modelo e ajudar o anunciante a otimizar sua campanha.

Um exemplo de situação que evidencia como é conveniente fazer uso de informações a priori no marketing digital é o de uma empresa que anuncia no estado São Paulo e pretende anunciar no Rio de Janeiro. Tal empresa pode utilizar, por exemplo, o planejador de palavraschave do google para saber quantas buscas por suas palavras-chave são feitas no Rio de Janeiro e, com isto, ter uma ideia, por exemplo, do Budget necessário para a campanha. Além disso, pode avaliar os melhores horários, dias da semana e utilizar essas informações e toda sua experiência para ajudar a montar a campanha de forma ótima.

Uma vantagem da Inferência Bayesiana é que toda a incerteza é tratada através de probabilidade, de modo que, basicamente, o procedimento Bayesiano é muito simples: utilizase informação a priori sob algo incerto na natureza (descrita numa distribuição a priori) e com 
o uso da amostra (dados estatísticos) atualiza-se a incerteza sobre esse fenômeno utilizando o teorema de Bayes, ou seja, efetuando cálculos de probabilidade, conforme será detalhado a seguir, para a obtenção de novas probabilidades descritas na distribuição que chamaremos de posteriori.

\subsubsection{Teorema de Bayes}

O Teorema de Bayes é o procedimento probabilístico utilizado pela Inferência Bayesiana para atualizar a incerteza sobre determinado fenômeno após se observar os dados. Ele utiliza o conhecimento prévio do problema (distribuição a priori) e combina com a informação proveniente dos dados (verossimilhança) e, finalmente, atualiza a incerteza (o conhecimento) sobre o evento através da distribuição a posteriori. Mais formalmente:

Seja $B_{1}, B_{2}, \ldots, B_{n}$ uma partição de $\Omega$, com $P\left(B_{i}\right)>0 \forall i=1,2, \ldots, n$. Seja $A$ um evento com $P(A)>0$. Então, para todo $i=1, \ldots, n$,

$$
P\left(B_{i} \mid A\right)=\frac{P\left(A \mid B_{i}\right) P\left(B_{i}\right)}{\sum_{j=1}^{n} P\left(A \mid B_{j}\right) P\left(B_{j}\right)}
$$

Por exemplo suponha que, três máquinas, A, B e C produzem 50\%, 30\% e 20\%, respectivamente, do total de peças de uma fabrica. Considere ainda que as percentagens de produção defeituosa de cada uma dessas máquinas são 3\%, 4\% e 5\% respectivamente. Se uma peça selecionada é defeituosa, qual a probabilidade dela ser retirada de cada máquina?

Seja $X$ o evento da peça ser defeituosa (dado estatístico). Portanto, gostaríamos de obter $P(A \mid X), P(B \mid X)$ e $P(C \mid X)$. Pelo Teorema de Bayes, tem-se que:

$$
\begin{aligned}
& P(A \mid X)=\frac{0,5 \times 0,03}{0,5 \times 0,03+0,3 \times 0,04+0,2 \times 0,05}=0,41 \\
& P(B \mid X)=\frac{0,3 \times 0,04}{0,5 \times 0,03+0,3 \times 0,04+0,2 \times 0,05}=0,32 \\
& P(C \mid X)=\frac{0,2 \times 0,05}{0,5 \times 0,03+0,3 \times 0,04+0,2 \times 0,05}=0,27
\end{aligned}
$$

Ou seja, ao se observar uma peça defeituosa, a incerteza sobre qual máquina a produziu é atualizada. O teorema de Bayes é utilizado na Inferência Bayesiana para atualização de incerteza como no exemplo acima. Outros exemplos serão mostrados na próxima seção. 


\subsubsection{Procedimento Bayesiano e Estimação Bayesiana}

O Teorema de Bayes também pode ser aplicado de forma mais geral, de todo modo o passo a passo proposto pelo Teorema de Bayes, que combina a informação da priori com a verossimilhança para atualizar a nossa incerteza através da posteriori será chamado de procedimento Bayesiano. Mais formalmente:

Seja $X_{1}, X_{2}, \ldots, X_{n}$ uma amostra de uma distribuição $f(x \mid \theta)$ e suponha que $\pi(\theta)$ representa nossa crença, a priori, sobre $\theta$. Então, aplicando o teorema de Bayes, nossa distribuição a posteriori de $\theta$ é

$$
\pi\left(\theta \mid x_{1}, x_{2}, \ldots, x_{n}\right)=\frac{f\left(x_{1}, x_{2}, \ldots, x_{n} \mid \theta\right) \pi(\theta)}{\int f\left(x_{1}, x_{2}, \ldots, x_{n} \mid \theta\right) \pi(\theta) d \theta}
$$

A distribuição a priori, $\pi(\theta)$, expressa nossa incerteza inicial sobre $\theta$ e a distribuição a posteriori, $\pi\left(\theta \mid x_{1}, \ldots, x_{n}\right)$, representa a crença revisada sobre $\theta$, após obtermos a informação da amostra $x_{1}, \ldots, x_{n}$. Note que $\int f\left(x_{1}, x_{2}, \ldots, x_{n} \mid \theta\right) \pi(\theta) d \theta$ não depende de $\theta$, e então, simplificadamente tem-se que

$$
\pi\left(\theta\left|x_{1}, \ldots, x_{n}\right| \theta\right) \propto L_{x}(\theta) \pi(\theta)
$$

na qual $L_{x}(\theta)=f\left(x_{1}, \ldots, x_{n} \mid \theta\right)$ é chamada de função de verossimilhança de $\theta$ gerada por $x=\left(x_{1}, \ldots, x_{n}\right)$.

Um dos possíveis objetivos da inferência é obter estimativas pontuais para um determinado parâmetro. A distribuição a posteriori atualiza a incerteza sobre o parâmetro de interesse. Entretanto, a posteriori é uma distribuição de probabilidade e não um valor especifico para $\theta$. Então, para se obter estimativas pontuais, é necessário calcular estatísticas da distribuição a posteriori que serão utilizadas como estimativas para o parâmetro de interesse. Usualmente, tais estatísticas são determinadas por minimização de funções de perdas.

Há várias funções de perdas que podem ser utilizadas para se obter estimadores pontuais de um parâmetro (para mais informações sobre funções de perdas, ver (DeGroot, 1970)). Dentre as principais funções de perda, a mais utilizada é a perda quadrática, $L(d, \theta)=$ $(d-\theta)^{2}$, que é minimizada pela média da distribuição posteriori de $\theta$ dado $x$, chamada de estimativa de Bayes sob a perda quadrática. Assim, após se obter a posteriori para $n$ 
observações, basta utilizar a média da correspondente distribuição a posteriori que esta será a estimativa de Bayes de $\theta$ sob a perda quadrática.

Exemplo: Um e-commerce vai criar um anúncio para um produto e para uma nova palavra-chave. Pois, em geral, um bom anúncio possui $C T R$ por volta de 0,10 . Seja $\theta$ o parâmetro de interesse que a empresa gostaria de estimar: $\theta$ representa o $C T R$ do novo anúncio. Como a empresa supõe, com base na sua experiência, sabe que o anúncio deve ter um $C T R$ pequeno, então resolve utilizar uma distribuição a priori $\operatorname{Beta}(1,9)$ para $\theta$. Sabese que a campanha teve 669 Impressões e para cada impressão considera-se uma variável aleatória de Bernoulli $X$ que representa a ocorrência de um clique: um clique como sucesso e o não clique como fracasso. Portanto, a distribuição posteriori para $\theta$ é dada por

$$
\pi\left(\theta\left|x_{1}, \ldots, x_{n}\right| \theta\right) \propto L_{x}(\theta) \pi(\theta)
$$

No caso, $n=669 \mathrm{e}$

$$
L_{x}(\theta)=f\left(x_{1}, \ldots, x_{n} \mid \theta\right)=\prod_{i=1}^{669} \theta^{x_{i}}(1-\theta)^{1-x_{i}}=\theta^{\sum x_{i}}(1-\theta)^{669-\sum x_{i}}
$$

onde $\sum x_{i}$ é o número de cliques observados, vamos supor que após se observar a amostra obteve-se $\sum x_{i}=13$. Assim,

$$
\pi\left(\theta \mid x_{1}, \ldots, x_{669}\right) \propto \theta^{13}(1-\theta)^{656} \times(1-\theta)^{8} \propto \theta^{13}(1-\theta)^{664}
$$

Ou seja, $\theta \mid x_{1}, \ldots, x_{669} \sim \operatorname{Beta}(14,665)$ e a correspondente estimativa de Bayes para $\theta$ é

$$
\hat{\theta}=E\left[\theta \mid x_{1}, \ldots, x_{669}\right]=\frac{14}{14+665} \approx 2 \%
$$

Inicialmente esperava-se que a taxa de cliques fosse por volta de 0,10, entretanto, após se observar os dados e atualizar a incerteza através da posteriori, conclui-se que o $C T R$ esperado é de 0.02 , então este anúncio não é um bom anúncio comparado com o $C T R$ que a empresa considera bons. 


\subsection{Teoria da Decisão}

Diariamente, o ser humano desde o momento que acorda até a hora que vai dormir toma diversas decisões, desde as mais simples até outras mais complicadas. Cada vez que uma escolha é feita, automaticamente, abre-se mão de todas as demais escolhas possíveis e recebe-se todos os benefícios e malefícios da decisão tomada. Algumas decisões são tomadas automaticamente em função de certos hábitos enquanto que outras são tomadas mais racionalmente.

Dentro deste contexto, surge o questionamento de como melhorar a tomada de decisão para se fazer escolhas melhores. Basicamente, a Teoria da Decisão Bayesiana proporciona um modo racional de fazer uma escolha, no qual o tomador das decisões consegue escolher dentre um conjunto de escolhas fixadas de antemão aquela decisão que mais lhe agrada. No caso deste trabalho, a melhor decisão é a que proporcionar o melhor retorno financeiro (esperado). A Teoria da Decisão Bayesiana comumente envolve os seguintes elementos.

Seja $D$ o espaço de decisões. Cada escolha de um elemento de $D$ induz incerteza sobre eventos. De modo mais geral, seja $d \in D$ uma possível decisão no conjunto de decisões. A escolha de $d$ induz um conjunto de "loterias"sobre um conjunto de recompensas $R$. O conjunto de recompensas não é necessariamente constituído de recompensas financeiras. Por exemplo, o espaço de decisões pode ser o conjunto de filmes disponíveis para assistir no netflix e a recompensa pode representar o quanto satisfeito o agente decisor fica ao assistir cada filme. De forma geral, a Teoria da Decisão estuda como escolher de forma ótima, dentro o conjunto de decisão $D$, aquela que, num certo sentindo, maximiza a satisfação do agente decisor.

No caso da netflix, cada filme proporciona uma recompensa diferente ao agente decisor, entretanto antes de escolher um título, não se sabe se ele vai detestar, ou não gostar, ou gostar ou amar determinado filme. Então cada título induz um conjunto de recompensas aleatórias para cada filme que possui uma probabilidade induzida dentro desse conjunto de recompensas. Do mesmo modo, no caso deste trabalho, a principal decisão a ser tomada é a escolha do custo por clique máximo, $C P C M$. Vamos supor que a cada visualização do anúncio é como se fosse lançado uma moeda com probabilidade $p$ de haver um retorno 
positivo. Entretanto, cada escolha do $C P C M(d \in D)$ induz uma probabilidade diferente de retorno, ou seja, um $p$ diferente tal que $p=f(C P C M)$.

Tradicionalmente, o problema de decisão pode ser representado através da seguinte forma $(\mathcal{D}, \Theta, U, \mathbb{P})$, no qual $\mathcal{D}$ representa o espaço de decisão, $\Theta$ representa os estados da natureza (possíveis valores de $\theta$ ), $U$ representa a função de utilidade (detalhada na seção seguinte) associada ao problema de decisão e $\mathbb{P}$ representa a incerteza sobre $\theta$ do qual é induzida, por cada decisão do espaço de decisões, uma recompensa aleatória (loteria). O problema de decisão também pode ser avaliado através de funções de perdas, na qual, neste contexto, a função utilidade é menos a função perda, ou seja, $L(\theta)=-U(\theta)$. Sobre este novo contexto, a decisão de Bayes é aquela que minimiza a perda esperada. Este trabalho não considerará funções de perda na tomada de decisão e maiores informações são encontradas em DeGroot (1970).

\subsubsection{Utilidade}

A probabilidade nasceu do estudo dos jogos de azar com o livro Liber de Ludo Aleae de Cardano 1663. Um dos objetivos do estudo era saber quanto se ganhava a cada partida em média e, com isto, foi introduzido o conceito de esperança matemática. Entretanto, várias criticas surgiram pelo fato de apenas se analisar a esperança para tomada de decisão e por não se levar em conta a percepção do quanto o dinheiro "vale"(utilidade) para um indivíduo. E devido a estas criticas originou-se o conceito de utilidade para medir o grau de satisfação a respeito de um conjunto de recompensas.

Como vimos, o principal objetivo da teoria da decisão é escolher um elemento dentro um conjunto de possíveis ações (espaço de decisão) de modo a maximiza a satisfação do agente decisor. Toda escolha de um elemento do espaço de decisão induz uma loteria sobre o espaço de recompensas, que de forma geral, representa a satisfação (incerta) do agente decisor segundo a qual cada recompensa pode ser preterida por outra pelo agente decisor. Uma forma de quantificar tal recompensa é através da medida de utilidade.

A utilidade representa o quanto vale ou é gratificante uma recompensa para o agente decisor. Por exemplo, ganhar 10 reais provavelmente é preferível a 1 real. Entretanto, é importante ressaltar que utilidade não é necessariamente uma função linear. Por exemplo, 
um trabalhador que recebe 500 reais por mês de trabalho vai ficar muito mais contente ao receber um aumento de 500 no salário do que um outro trabalhador que recebe 12000. Mais detalhes em DeGroot (1970) e em Inoue (2009). Na seção seguinte, discutiremos como comparar duas decisões.

\subsubsection{Principio da Utilidade Esperada}

Um agente decisor deve decidir entre quais decisões deve tomar dentro de um espaço de decisões $D$. Cada escolha dentre desse conjuntos de decisões induz uma probabilidade $P$ de se obter uma recompensa dentro de um conjunto de recompensas $R$. Cada recompensa $r$ gera no agente decisor um grau de satisfação diferente uma da outra, e essa satisfação é medida através da função utilidade $U$. Neste contexto, DeGroot (1970) mostra que, sob certas condições, o agente decisor prefere a decisão $d_{2}$ em detrimento a decisão $d_{1}\left(d_{1} \precsim * d_{2}\right)$, se e somente se, a utilidade esperada sob $d_{2}$ é maior ou igual a utilidade esperada sob $d_{1}$. Isto é

$$
d_{1} \precsim^{*} d_{2} \Leftrightarrow E\left(U \mid P_{d_{1}}\right) \leq E\left(U \mid P_{d_{2}}\right)=\int_{R} U(r) d P_{d_{1}}(r) \leq \int_{R} U(r) d P_{d_{2}}(r)
$$

onde

$$
\int_{R} U(r) d P_{d_{i}}(r)
$$

denota o valor esperado de $U$ segundo $P_{d_{i}}, i=1,2$.

Por este ponto de vista, o objetivo é escolher a decisão $a \in D$ que maximiza a utilidade esperada

$$
\mathcal{U}(a)=E\left(U \mid P_{a}\right)=\int_{R} U(r) d P_{a}(r)
$$

Ou seja, a decisão ótima $a^{*}$, chamada de decisão de Bayes, é aquela maximiza a utilidade esperada. Então

$$
a^{*}=\operatorname{argmax}\{\mathcal{U}(a)\}
$$


O critério descrito acima é denominado de principio da maximização da utilidade esperada.

\subsubsection{Risk Taker e Risk Averse}

Como já foi explicado na seção 3.4.1, os seres humanos avaliam o retorno financeiro de maneiras diferentes, traduzidas por funções de utilidade distintas. Para explicar tais diferenças será apresentado um exemplo de Inoue (2009). Um exportador compra por R\$ 9000.00 um tapete muito valioso e que durante o transporte há probabilidade $3 \%$ de ser extraviado. Por quanto este exportador estaria disposto a pagar por um seguro para o tapete?

\begin{tabular}{r|c}
\hline Recompensa & Probabilidade \\
\hline 0,00 & 0,97 \\
$-9.000,00$ & 0,03 \\
\hline
\end{tabular}

Tabela 3.1: Risco de Sinistro

Depende, pois, neste contexto, tem-se que $E($ Recompensa $)=-9.000,00 \times 0,03=$ $-270,00$. Se o agente decisor achar que a probabilidade de perda é muito pequena contratando o seguro e que neste caso um seguro não é necessário ou que ele poderia até pagar desde que seja um valor menor do que $\mathrm{R} \$ 270,00$ então o agente decisor é considerado como Risk Taker. Entretanto, se para o agente decisor for mais importante ficar reguardado mesmo pagando mais do que 270 reais do que poder ter um prejuízo de 9 mil então ele é considerado Risk Averse. Por fim, se o agente decisor aceita pagar um seguro mas somente se ele for exatamente igual a R\$270,00 então ele é Risk Neutral. Note que fazer um seguro seria o mesmo que obter uma recompensa com valor negativo do seguro com probabilidade 1. Assim, um Risk Neutral aceita pagar $\mathrm{R} \$ 270,00$, que é o valor esperado do prejuízo, e um Risk Averse aceita pagar um valor maior para ter certeza que não vai perder o tapete. Por outro lado, o Risk Taker até aceita viajar sem seguro, ou pagar um seguro menor do que R $\$ 270,00$.

Em geral, uma pessoa é suscetível ao risco, ou seja, Risk Taker, se ela prefere investimentos mais arriscados e com recompensa maiores, enquanto que uma pessoa que prefere recompensas menores mas com pouco risco seria avessa ao risco, ou seja, Risk Averse. Segundo (DeGroot, 1970), se uma pessoa é Risk Taker, via de regra, ela possui função de 
utilidade convexa, enquanto que uma pessoa Risk Averse possui função utilidade concava. Basicamente, uma pessoa Risk Averse aceita receber uma recompensa menor do que a recompensa esperada, enquanto que alguém Risk Taker prefere correr mais risco para receber uma recompensa maior que a recompensa esperada.

\subsection{Otimização de Monte Carlo por Exploração Estocás- tica}

Basicamente, o que foi mostrado até agora, é que, para se escolher a decisão ótima, basta encontrar dentro do espaço de decisões aquela que maximiza a utilidade esperada em relação a um conjunto de recompensas, ou seja, a decisão de Bayes. Entretanto, nem sempre é trivial realizar a maximização da utilidade esperada, ainda mais em problemas como o proposto neste trabalho, no que há vários tipos de restrições que serão detalhadas no próximo capítulo.

Para fazer otimização de funções mais elaboradas, geralmente é utilizado métodos numéricos como o de Newton-Raphson (Louzada (2014)). Entretanto, métodos como os de Newton-Raphson necessitam que a função seja derivável e contínua em todo seu domínio, algo que nem sempre pode ser garantido. Então, para resolver este problema será utilizado métodos de otimização de Monte Carlo.

Há diversos métodos de Otimização de Monte Carlo na literatura e sabe-se que por mais eficientes que sejam os métodos de Monte Carlo, eles são muito custosos computacionalmente. No entanto, para este trabalho, em vez de ser feito um estudo do método mais eficiente, buscou-se aquele que seria mais simples, que é o método de otimização de Monte Carlo por exploração estocástica (Kim et al. (2006)).

O método de Monte Carlo por exploração estocástica possui um pré-requisito: que a função a ser maximizada seja limitada dentro de um intervalo, o que acontece neste caso, pois, na pior das hipóteses, o CPCM está limitado ao intervalo (0, Budget) e o valor total de investimento está limitado também em (0,Budget) conforme será apresentado no próximo capítulo. Então, este método será suficiente para resolver este problema. Basicamente, o método de otimização de Monte Carlo por exploração estocástica gera dados uniformes dentro do domínio da função limitada e o valor máximo da função dentre os dados gerados 
converge ao máximo da função quase certamente. Para conhecer maiores detalhes sobre otimização de Monte Carlo, consultar Kim et al. (2006).

Mais formalmente, seja $f$ a função que se deseja maximizar num intervalo fechado $[a, b]$. Se for simulada uma sequência $u_{1}, u_{2}, \ldots$ da distribuição uniforme $U(a, b)$, então a função $f^{*}\left(u_{1}, \ldots, u_{n}\right)=\max \left\{f\left(u_{1}\right), \ldots, f\left(u_{n}\right)\right\}$ converge quase certamente (quando $n \rightarrow \infty$ ) para o máximo da função $f$. 


\section{Capítulo 4}

\section{Decisão Ótima no Google Ads}

\subsection{Introdução}

O objetivo deste capítulo é encontrar a configuração ótima que maximize o lucro esperado para uma campanha na rede de pesquisa no google Ads através da teoria da decisão bayesiana. Neste trabalho será considerada a função utilidade linear, ou seja, que o agente tomador de decisão é risk neutral.

\subsection{Espaço de Decisão}

O espaço de decisão representa um conjunto de ações que podem ser tomadas pelo agente decisor. Considerando-se a rede de pesquisa do google ads, o agente decisor deve escolher como alocar seu budget fixo nas diferentes configurações (descritas a seguir), e determinar o lance máximo (CPCM) que deseja pagar por clique para cada uma das as possíveis configurações, e escolher o melhor anúncio e a melhor página de destino para cada configuração disponível. As configurações disponíveis serão detalhadas a seguir.

\subsubsection{Conjunto de configurações}

Dentro do Google Ads, é possível personalizar as campanhas por palavra-chave, cidade, dispositivo, dia da semana e horários. Nesta seção, será detalhado cada um dos possíveis elementos de uma configuração. 


\section{Palavra-Chave}

A palavra-chave nada mais é do que a palavra que o usuário digita antes de visualizar o anúncio. Dentro deste trabalho, supõe-se que o agente decisor escolhe seu conjunto de palavras-chave. Neste contexto, o procedimento desenvolvido neste capítulo determinará quais palavras-chave serão ou não utilizadas na campanha publicitária.

\section{Cidade}

O google ads permite segmentar os anúncios em relação ao local onde a pesquisa é realizada através do CEP, bairro, cidade e estado. Essa segmentação é feita através da geolocalização através do endereço de IP. Entretanto, este tipo de geolocalização é muito impreciso e, por causa disto, este trabalho utilizará apenas a cidade como parâmetro da localização.

A localização do usuário afeta diretamente a forma como ele reage a uma propaganda e a conversão. Por exemplo, se um e-commerce possui um estoque em um determinado local, usuários distantes desse local ficam menos propensos a adquirir o produto pelo valor do frete elevado. Além disto, cidades diferentes possuem populações, hábitos, valores e costumes diferentes. Por tudo isto, é fundamental personalizar o lance e o budget em relação a cidade.

\section{Dispositivo}

O agente decisor pode configurar sua campanha para dar lances personalizados para celulares e outros dispositivos. Algo importante de se ressaltar é que dispositivos diferentes proporcionam experiências de navegação diferentes para os usuários e, consequentemente, interferem diretamente na maneira que é realizada uma conversão.

\section{Dia da Semana}

A quantidade de buscas realizadas nos diferentes dias da semana não é a mesma, assim como a quantidade de concorrentes. Por exemplo, para um produto B2B (business to business), é mais comum buscas durante o meio da semana do que nos finais de semana. Além do que, pode ser que a concorrência pelas palavras-chave mudem durante os dias da semana, o que faz com que os índices $C T R$ e $C P C$ se alterem. 


\section{Horário}

É uma prática comum no mercado configurar as campanhas em determinados horários, pois a quantidade de buscas muda dependendo do horário e, às vezes, as empresas que anunciam possuem um departamento de atendimento que funciona em apenas um horário. Além disso, o fato de que um anunciante determina um budget fixo para utilizar durante o dia e assim que esse valor é atingido os seus anúncios param de ser exibidos faz com que certos horários possam ter uma quantidade menor de concorrentes fazendo com que seja preciso pagar menos para obter melhores posições, o que, potencialmente, representa um aumento do $C T R$ e uma diminuição do $C P C$.

\section{Espaço de Configurações}

Dentro da plataforma do Google Ads, algumas das configurações descritas acima fazem com que os anúncios sejam visto por uma quantidade maior de pessoas, enquanto que outras configurações restringem e personalizam o espaço de decisão. Então quando um anunciante adiciona uma nova palavra-chave está automaticamente abrangendo o número maior de pessoas atingidas pelo anuncio, enquanto que, quando o anunciante determina os horários e os lances dos seus anúncios nestes horários está automaticamente restringindo a quantidade de buscas e personalizando o espaço de decisão.

Como o objetivo deste trabalho também engloba saber como vai ser alocado um budget fixo dentre as configurações, sendo aquelas que forem restritivas podem ou não receber investimento então é preciso garantir que sejam avaliadas as configurações preestabelecidas. Por causa disto, algumas configurações serão classificadas como Aditivas e outras de Particionais, pois as aditivas proporcionam uma quantidade maior de buscas e as particionais permitem particionar o espaço para que seja possível personalizar as decisões.

Seja $S$ o espaço de configurações (settings) que será composto pelas configurações aditivas $A_{1}$ e $A_{2}$ e particionais $P_{1}, P_{2}$ e $P_{3}$. Onde $A_{1}, A_{2}, P_{1}, P_{2}$ e $P_{3}$ representam respectivamente os conjuntos das palavras-chave $\left(A_{1}\right)$, das cidades $\left(A_{2}\right)$, dos dispositivos $\left(P_{1}\right)$, dos dias da semana $\left(P_{2}\right)$ e dos horários $\left(P_{3}\right)$ que o anunciante pode escolher ao configurar sua campanha no Google Ads.

Para cada elemento $s \in S$ tal que $s=\left(a_{1}, a_{2}, p_{1}, p_{2}, p_{3}\right)$ do produto cartesiano $A_{1} \times A_{2} \times$ 
$P_{1} \times P_{2} \times P_{3}$, o agente decisor deve tomar um conjunto de decisões que serão detalhadas na próxima seção: budget, $C P C M$, anúncio e página de destino. Note que, utilizando o princípio fundamental da contagem, que o anunciante deve tomar um conjunto de 4 decisões para

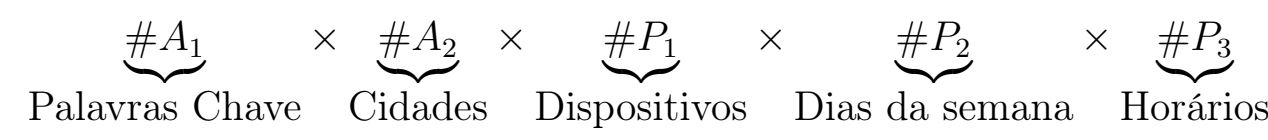
configurações, onde o simbolo \#S representa a cardinalidade do conjunto $S$.

\subsubsection{Elementos do Espaço de Decisão}

Será descrito detalhadamente cada componente do vetor de decisão, esse vetor possui dimensão 4 para cada configuração $s$. A decisão consiste em escolher para cada configuração $s$ um anúncio, uma Landing Page, determinar o budget e o CPCM.

\section{Anúncio}

Um anunciante pode criar mais de um anúncio por palavra-chave e cidade. Por exemplo, um anúncio com o nome da cidade geralmente gera mais relevância para pessoas daquela cidade pois especifica o público-alvo. É evidente que certos anúncios podem funcionar melhor em determinados contextos do que em outros. Então, o anunciante deve decidir qual será o anúncio utilizado para cada contexto.

\section{Landing Page}

Landing Page nada mais é do que a página de destino do anúncio e representa a página web onde o usuário é direciona após clicar no anúncio. Neste trabalho, Landing Page e página de destino serão utilizadas como sinónimo.

É comum se testar a página de destino do mesmo modo que se testa o anúncio. Esse tipo de teste é conhecido como teste $A B$ porque vai direcionar o usuário, consecutivamente, para a página $A$ e depois para a $B$ com o intuito de verificar qual possui maior conversão.

Este tipo de teste também permite testar várias páginas ao mesmo tempo. Tais páginas podem ser diferentes desde apenas a cor de botão até o conteúdo completo. 
A página de destino, assim como o anúncio, está diretamente relacionada com o índice de qualidade de determinada palavra-chave, ou seja, anúncios mais atrativos e relevantes para o usuário, assim como páginas de fácil navegação e com melhor experiência de navegação, fazem com que o índice de qualidade aumente e, consequentemente, diminua o $C P C$.

\section{Budget}

O budget representa quanto o anunciante vai alocar em cada configuração. É importante ressaltar que no caso de uma campanha publicitária há limitações orçamentárias, de modo que é importante investir em configurações mais rentáveis em detrimento das menos lucrativas.

\section{CPCM}

O custo por clique máximo que o anunciante está disposto a pagar é também conhecido como lance máximo por clique. Este valor representa o valor máximo que será cobrado por clique em uma campanha publicitária PPC (pay per click).

\subsubsection{Tamanho do Espaço de Decisão}

Conforme foi detalhado na Seção 4.2.2, há um conjunto de configurações possíveis e o agente decisor deve tomar 4 decisões para cada elemento do espaço de configurações.

Por exemplo, suponha que uma empresa pode escolher as palavras-chave 'A' ou 'B', anunciar nas cidades de São Paulo, Rio de Janeiro ou Curitiba, para os dispositivos celular ou outros, nos dias úteis (segunda até sexta) e no horário comercial (8:00 às 18:00). Além disso, a empresa criou anúncios e páginas de destino distintos para cada palavra-chave e cidade. A tabela 4.1 ilustra a estrutura do problema de decisão nesse caso.

\begin{tabular}{ccccc|cc}
\hline \multicolumn{4}{c|}{ Espaço de Configurações } & \multicolumn{2}{c}{ Quantidade de } \\
\hline KW & Cidade & Dispositivo & Dia da Semana & Horário & Anúncios & Página de Destino \\
\hline A & São Paulo & Celular & Segunda & 8 às 9 & 4 & 4 \\
A & São Paulo & Celular & Segunda & 9 às 10 & 4 & 4 \\
$\vdots$ & $\vdots$ & $\vdots$ & $\vdots$ & $\vdots$ & $\vdots$ & $\vdots$ \\
B & Curitiba & Outros & Sexta & 17 às 18 & 2 & 2 \\
\hline
\end{tabular}

Tabela 4.1: Quantidade de anúncios e Página de Destino segundo as configurações 
Nesse caso, o agente decisor deve escolher para cada um dos elementos do produto cartesiano $A_{1} \times A_{2} \times P_{1} \times P_{2} \times P_{3}$ o lance máximo que deseja pagar $(C P C M)$, o valor do investimento $(B)$, um anúncio $(A d)$ e uma página de destino $(L d)$.

Para simplificar a notação o conjunto formado pelo produto cartesiano $A_{1} \times A_{2} \times$ $P_{1} \times P_{2} \times P_{3}$ de configurações será representado por $S$. Do mesmo modo, um elemento do produto cartesiano será representado por s. Quando o texto referenciar a configuração $s=\left(a_{1}, a_{2}, p_{1}, p_{2}, p_{3}\right)$, quer dizer que está se falando da palavra-chave $a_{1}$, na cidade $a_{2}$, no dispositivo $p_{1}$, no dia da semana $p_{2}$ e no horário $p_{3}$. Do mesmo modo, $s_{A d_{i} L d_{j}}$ denota para a configuração $s$ com o anúncio $i$ e a landing Page $j$.

Nesse caso, os conjuntos definidos por $A d_{s}$ e $L d_{s}$ representam os conjuntos dos anúncios e páginas de destino para a configuração $s \in S$. Temos que um elemento típico do espaço de decisão é $d=\left(\left(a d_{s}, l d_{s}, b_{s}, C P C M_{s}\right): s \in S\right)$, onde $a d_{s} \in A d_{s}, l d_{s} \in L d_{s}, b_{s} \in[0, B]$ e $C P C M_{s} \in[0, B]$, onde $B$ é o budget total disponível do agente decisor. Note que os valores de $b_{s}$ devem satisfazer

$$
\sum_{s \in S} b_{s} \leq B
$$

Na tabela 4.1, cada linha representa um elemento $s$ do conjuntos de configurações $S$ em que o agente decisor deve escolher um anúncio, uma página de destino, o valor que será investido e o lance máximo por clique. Por exemplo, para a primeira linha, tem-se que o agente decisor deve escolher um anúncio entre os 4 anúncios disponíveis, deve escolher uma landing page das 4 disponíveis, determinar o lance máximo por clique $(C P C M)$ que vai utilizar e o budget que será investido para a palavra-chave 'A', na cidade de São Paulo, para celulares, na segunda feira, no horário das 8 às 9.

\subsection{Funil de Vendas}

O termo funil de vendas é muito comum na área de comercial e no marketing digital. Através do Funil de Vendas é possível entender como funciona o processo de vendas. Quando um usuário entra no funil, ele pode sair ou do processo ou passar para uma próxima fase, em função de alguns usuários saírem no meio do caminho que este processo é chamado de 
funil.

\section{Primeira fase: Impressão}

Quando um usuário digita por uma palavra-chave no google e visualiza o anúncio ele entra na primeira fase do funil que é chamada de impressão. Aqui é importante ressaltar que cada usuário que visualiza o anúncio é diferente de outros, então é razoável supor que cada visualização é independente da outra, portanto a reação de cada usuário é independente da outra.

\section{Segunda fase: Clique}

Quando um usuário visualiza o anúncio, ele pode clicar, ou ir embora. Se ele clicar no anúncio, automaticamente é direcionado para a página de destino da propaganda. Ou seja, ao realizar o clique o usuário entra na segunda fase. Note que, assim como na etapa anterior, uma pessoa clica no anúncio independentemente se outra clicar ou ir embora, então também cada clique é independe dos demais. Além disso, não é razoável supor que existe dependência entre a quantidade de pessoas que visualizam o anúncio e a frequência com que as mesmas clicam no anúncio.

Algo que é muito importante de ser ressaltado é que a campanha é paga a cada clique. Então conforme cliques vão ocorrendo um valor é descontado do budget até que ele seja totalmente esgotado.

\section{Terceira fase: Conversão ou Venda}

Como já foi explicado, assim que uma pessoa clica no anúncio é direcionado para Landing Page e ao chegar lá pode deixar o site ou realizar uma ação de interesse denominada de conversão. Se esse usuário converter, ele automaticamente entra na terceira e ultima etapa. Note a frequência das pessoas que convertem independem da frequência e da quantidade dos cliques e também da quantidade de buscas. 


\subsubsection{Estrutura Probabilística do Funil de Conversão}

Seja $N_{a_{1} a_{2}}$ a variável aleatória que representa a quantidade de buscas em um determinado mês pela palavra chave $a_{1}$ que ativa o anúncio na cidade $a_{2}$, com $N_{a_{1} a_{2}} \in \mathbb{N}$. Seja $\lambda_{a_{1} a_{2}}$ a taxa médias das buscas pela palavra chave $a_{1}$ na cidade $a_{2}$ durante determinado mês então suporemos que

$$
\begin{gathered}
\lambda_{a_{1} a_{2}} \sim \operatorname{Gama}\left(\varphi_{a_{1} a_{2}}, \vartheta_{a_{1} a_{2}}\right) . \\
N_{a_{1} a_{2}} \mid \lambda_{a_{1} a_{2}} \sim \operatorname{Poisson}\left(\lambda_{a_{1} a_{2}}\right)
\end{gathered}
$$

Seja $N_{s}$ a quantidade de buscas na configuração $s=\left(a_{1}, a_{2}, p_{1}, p_{2}, p_{3}\right)$. Note que o conjunto de configurações $s$, fixando $a_{1}$ e $a_{2}$, cria uma partição do espaço em relação a $P_{1} \times P_{2} \times P_{3}$, então

$$
N_{a_{1} a_{2} P_{1} P_{2} P_{3}} \mid N_{a_{1} a_{2}} \sim \operatorname{Multinomial}\left(N_{a_{1} a_{2}}, \beta_{a_{1} a_{2} P_{1} P_{2} P_{3}}\right)
$$

onde

$$
\beta_{a_{1} a_{2} P_{1} P_{2} P_{3}} \sim \operatorname{Dirichlet}\left(\tau_{1}, \ldots, \tau_{k}\right)
$$

com $k=\# P_{1} \times \# P_{2} \times \# P_{3}-1$. Note que, a palavra-chave $a_{1}$ e a cidades $a_{2}$ estão fixas. $\mathrm{O}$ resultado acima é proveniente da seguinte relação:

$$
\begin{gathered}
Y_{1} \sim \operatorname{Gama}\left(\alpha_{1}, \theta\right), \ldots, Y_{K+1} \sim \operatorname{Gama}\left(\alpha_{k}, \theta\right) \\
V=\sum_{i=1}^{k+1} Y_{i}=\operatorname{Gama}\left(\sum_{i=1}^{k+1} \alpha_{i}, \theta\right)
\end{gathered}
$$

então,

$$
X=\left(X_{1}, \ldots, X_{k}\right)=\left(\frac{Y_{1}}{V}, \ldots, \frac{Y_{k}}{V}\right) \sim \operatorname{Dirichlet}\left(\alpha_{1}, \ldots, \alpha_{k}\right)
$$

Marginalmente, tem-se que

$$
N_{s} \mid N_{a_{1} a_{2}} \sim \operatorname{Bin}\left(N_{a_{1} a_{2}}, \beta_{s}\right)
$$




$$
\beta_{s} \sim \operatorname{Beta}\left(\tau_{s}, \tau_{0}-\tau_{s}\right)
$$

onde $\tau_{0}=\sum_{1}^{k} \tau_{i}$. Portanto,

$$
N_{s} \mid \lambda_{a_{1} a_{2}}, \beta_{s} \sim \text { Poisson }\left(\lambda_{a_{1} a_{2}} \times \beta_{s}\right)
$$

O $\beta_{s}$ representa a proporção de busca da configuração $s$ em relação ao total de buscas pela palavra-chave $a_{1}$ na cidade $a_{2}$.

Sejam $I_{s_{a d_{i}}}, n_{s_{a d_{i}}}$ e $c_{s_{a d_{i} l d_{j}}}$, respectivamente, o número de impressões do anúncio $i$, a quantidade de cliques no anúncios $i$ e o total de conversões provenientes do anúncio $i$ na landing page $j$, para a configuração $s \in S$.

As impressões representam a quantidade de usuários que visualizam o anúncios. Deste modo, a quantidade de impressões é uma variável aleatória limitada superiormente pela quantidade de buscas, pois se houver budget suficiente a quantidade máxima de impressões $I_{s_{a d_{i}}}$ do anúnio $i$ na configuração $s$ será $N_{s_{a d_{i}}}$. Fora o caso onde isto ocorre, a variável pode ser vista como a quantidade de parcelas da soma aleatória de cada $C P C$ :

$$
B=\sum_{i=1}^{I_{a d_{i}}} c p c_{s_{a d_{i}}}
$$

onde, $c p c_{s_{a d_{i}}}$ representa o valor aleatório cobrado por cada clique. Note que, trabalhar diretamente com a quantidade de impressões é bastante complicado, então neste momento não será dado tanta importância para sua distribuição.

Como cada usuário clica no anúncio independente dos demais e condicionado a uma configuração $s$ a probabilidade do anúncio ser clicado é a mesma para todos os usuários e se adicionalmente considerarmos que cada clique seja considerado como sucesso e cada não clique como fracasso então a quantidade total de cliques pode ser vistas como

$$
n_{s_{a d_{i}}} \mid I_{s_{a d_{i}}} \sim \operatorname{Bin}\left(I_{s_{a d_{i}}}, C T R_{s_{a d_{i}}}\right)
$$

onde $C T R_{s_{a d_{i}}}$ é o click through rate da configuração $s$ do anúncio $i$ que representa a probabilidade do usuário clicar no anúncio e é função da escolha do $C P C M_{s_{a d_{i}}}$ pelo agente decisor. Por exemplo, se o anúncio $A d_{1}$ tiver 100 impressões e o $C T R$ do anúncio for de 0.8, 
ou seja, $I_{A d_{1}}=100$ e $C T R_{s_{a d_{1}}}=0.08$, então a quantidade de cliques que $n_{s_{a d_{1}}} \mid I_{s_{a d_{1}}=100}$ tem distribuição binomial $\operatorname{Bin}(100,0.08)$.

Do mesmo modo que o numero de cliques a quantidade de conversões condicionada a quantidade de cliques e a uma determinada configuração $s$ também pode ser considerado como ensaios de bernoulli Independentes, no qual sucesso representa uma conversão na landing page $j$ e fracasso se isto não ocorre, além disso, dado que um usuário na configuração $s$ clicou no anúncio $i$ a probabilidade dele converter na página de destino $j$ é a mesma e é igual a $C R_{s_{a d_{i} l d_{j}}}$, então

$$
c_{s_{a d_{i} l d_{j}}} \mid n_{s_{a d_{i}}}, C R_{s_{a d_{i} l d_{j}}} \sim \operatorname{Bin}\left(n_{s_{a d_{i}}}, C R_{s_{a d_{i} l d_{j}}}\right)
$$

como foi mencionado anteriormente a taxa de conversão é independente da quantidade de cliques e a taxa de conversão por conveniência matemática pode ser representada como

$$
C R_{s_{a d_{i} l d_{j}}} \sim \operatorname{Beta}\left(\nu_{s_{a d_{i} l d_{j}}}, \kappa_{s_{a d_{i} l d_{j}}}\right)
$$

Por exemplo, se uma campanha teve 100 cliques e a taxa de conversão for uma variável aleatória com distribuição $\operatorname{Beta}(1,9)$, então a distribuição de total de conversões condicionado ao numeros de cliques e a taxa de conversão será $c \mid n=100, C R \sim \operatorname{Bin}(100, C R)$, com $C R \sim \operatorname{Beta}(1,9)$

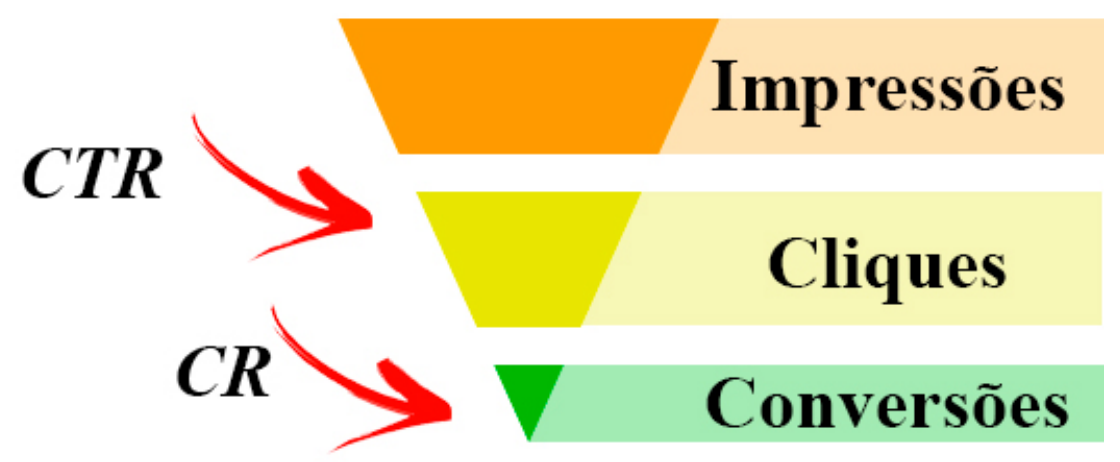

Figura 4.1: Funil de Vendas

O funil de vendas está representado pela figura 4.1. Ao analisar o funil, tem-se que para um número fixo de impressões uma maneira de melhorar as conversões é aumentando a taxa 
de cliques ou a taxa de conversões. Entretanto, ao se aumentar a taxa de cliques a campanha precisa de um investimento maior pois se paga por clique, enquanto que ao aumentar a taxa de conversão a campanha fica mais rentável pois a mesma quantidade de cliques produz mais conversão.

Portanto, a análise do funil de vendas mostra que o anunciante deve escolher um anúncio que possui uma taxa de clique boa, assim como uma página de destino com um boa taxa de conversão $\forall s \in S$ tal que se obtenha o maior lucro esperado.

\subsection{Ganho e Custo por Impressão (GPI e CPI)}

Sejam $G P I_{s_{a d_{i} l d_{j}}}$ e $C P I_{s_{a d_{i}}}$ respectivamente o ganho e o custo por conversão na configuração $s$ utilizando o anúncio $i$ e a landing page $j$. Sabe-se que o anunciante ganha $L_{a_{1}}$ a cada conversão e gasta $C P C_{s_{a d_{i}}}$, então para um anúncio $i$ e para a landing page $j$ o usuário converte se clicar no anúncio $i$ e converter na landing page $j$, do mesmo modo o anunciante gasta se um usuário clicar no anúncio $i$. Então para cada impressão a distribuição do $G P I_{s_{a d_{i} l d_{j}}} \mid C R_{s_{a d_{i} l d_{j}}}$ e do $C P I_{s_{a d_{i}}}$ é apresentada na Tabela 4.2.

\begin{tabular}{cc|cc}
\hline \multicolumn{2}{c|}{$C P I_{s_{a d_{i}}}$} & \multicolumn{2}{|c}{$G P I_{s_{a d_{i} l d_{j}}} \mid C R_{s_{a d_{i} l d_{j}}}$} \\
\hline $\mathrm{R} \$$ & Probabilidade & $\mathrm{R} \$$ & Probabilidade \\
\hline$C P C_{s_{a d_{i}}}$ & $C T R_{s_{a d_{i}}}$ & $L_{a_{1}}$ & $C T R_{s_{a d_{i}}} \times C R_{s_{a d_{i} l d_{j}}}$ \\
0 & $1-C T R_{s_{a d_{i}}}$ & 0 & $1-C T R_{s_{a d_{i}}} \times C R_{s_{a d_{i} l d_{j}}}$ \\
\hline
\end{tabular}

Tabela 4.2: Distribuição de probabilidade do $C P I_{s_{a d_{i}}}$ e do $G P I_{s_{a d_{i} l d_{j}}} \mid C R_{s_{a d_{i} l d_{j}}}$

Nos quais os valores esperados podem ser escritos como

$$
\begin{gathered}
E\left(C P I_{s_{a d_{i} l d_{j}}}\right)=C P C_{s_{a d_{i}}} \times C T R_{s_{a d_{i}}} \\
E\left(G P I_{s_{a d_{i} l d_{j}}}\right)=E\left(E\left(G P I_{s_{a d_{i} l d_{j}}} \mid C R_{s_{a d_{i} l d_{j}}}\right)\right)=L_{a_{1}} \times C T R_{s_{a d_{i}}} \times E\left(C R_{s_{a d_{i} l d_{j}}}\right)
\end{gathered}
$$

como $C R_{s_{a d_{i} l d_{j}}} \sim \operatorname{Beta}\left(\nu_{s_{a d_{i} l d_{j}}}, \kappa_{s_{a d_{i} l d_{j}}}\right)$, então

$$
E\left(G P I_{s_{a d_{i} l d_{j}}}\right)=L_{a_{1}} \times C T R_{s_{a d_{i}}} \times\left(\frac{\nu_{s_{a d_{i} l d_{j}}}}{\nu_{s_{a d_{i} l d_{j}}}+\kappa_{s_{a d_{i} l d_{j}}}}\right)
$$

onde $C P C_{s_{a d_{i}}}$ e $C T R_{s_{a d_{i}}}$ dependem da escolha de $C P C M_{s_{a d_{i}}}$ conforme argumentadas na 
seção 3.4. Assim, consideramos que existem funções $f$ e $g$ tais que $C P C_{s_{a d_{i}}}=f\left(C P C M_{s_{a d_{i}}}\right)$ e $C T R_{s_{a d_{i}}}=g\left(C P C M_{s_{a d_{i}}}\right)$

\subsection{Ganho e Gasto Esperado}

Sejam Ganho $_{s_{a d_{i} l d_{j}}}$ e Gasto ${ }_{s_{a d_{i}}}$ as variáveis aleatórias que representam respectivamente o ganho e o gasto na configuração $s$, do anúncio $i$ e da landing page $j$. Além disso, sabe-se que Ganho $_{s_{a d_{i} l d_{j}}}=c_{s_{a d_{i} l d_{j}}} \times L_{a_{1}}$ e Gasto sadi $_{s_{i}}=n_{s_{a d_{i}}} \times C P C_{s_{a d_{i}}}$ Portanto, tem-se que:

$$
\begin{gathered}
E\left(\text { Ganho }_{s_{a d_{i} l d_{j}}}\right)=E\left(c_{s_{a d_{i} l d_{j}}} \times L_{a_{1}}\right)=L_{a_{1}} \times E\left(c_{s_{a d_{i} l d_{j}}}\right) \\
E\left(\text { Gasto }_{s_{a d_{i}}}\right)=E\left(n_{s_{a d_{i}}} \times C P C_{s_{a d_{i}}}\right)=C P C_{s_{a d_{i}}} \times E\left(n_{s_{a d_{i}}}\right)
\end{gathered}
$$

onde

$$
\begin{gathered}
E\left(n_{s_{a d_{i}}}\right)=E\left[E\left(n_{s_{a d_{i}}} \mid I_{s_{a d_{i}}}\right)\right]=E\left(C T R_{s_{a d_{i}}} \times I_{s_{a d_{i}}}\right)=C T R_{s_{a d_{i}}} \times E\left(I_{s_{a d_{i}}}\right) \\
E\left(c_{s_{a d_{i} l d_{j}}}\right)=E\left[E\left(c_{s_{a d_{i} l d_{j}}} \mid n_{s_{a d_{i}}}, C R_{t j}\right)\right]=E\left(n_{s_{a d_{i}}} \times C R_{t j}\right) \stackrel{i n d}{=} E\left(n_{s_{a d_{i}}}\right) \times E\left(C R_{s_{a d_{i} l d_{j}}}\right) \\
E\left(c_{s_{a d_{i} l d_{j}}}\right)=C T R_{s_{a d_{i}}} \times E\left(I_{s_{a d_{i}}}\right) \times\left(\frac{\nu_{s_{a d_{i} l d_{j}}}}{\nu_{s_{a d_{i} l d_{j}}}+\kappa_{s_{a d_{i} l d_{j}}}}\right)
\end{gathered}
$$

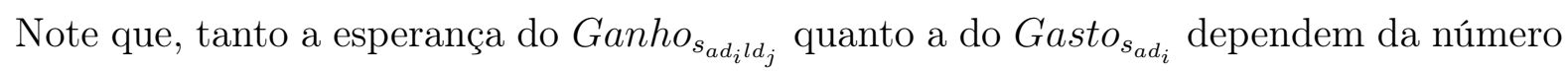
esperado de impressões, o mesmo será apresentado na próxima seção.

\subsection{Número Esperado de Impressões}

A quantidade de impressões que o anúncio recebe é uma variável aleatória que não tão simples para se achar sua distribuição, entretanto, sabe-se que ela é limitada superiormente pela quantidade de buscas em um certa configuração $s$, então caso o anunciante participe de todos os $N_{s}$ leilões utilizando o anúncio $i$ então $I_{s_{a d_{i}}}=N_{s}$ e o Gasto $s_{a_{a d_{i}}}$ atinge o seu supremo e neste caso pode ser calculado da seguinte forma, 


$$
\sup \text { Gasto }_{s_{a d_{i}}}=\sum_{k=1}^{I_{s_{a d_{i}}}} C P I_{s_{a d_{i} k}}=\sum_{k=1}^{N_{s}} C P I_{s_{a d_{i} k}}
$$

O $C P I_{s_{a d_{i} k}}$ é independente de $N_{s}$ pois só depende de $C P C_{s_{a d_{i}}} \times C T R_{s_{a_{i}}}$, que por sua vez, depende apenas da decisão do agente decisor. Então, tem-se que

$$
E\left(\sup \text { Gasto }_{s_{a d_{i}}}\right)=E\left(N_{s}\right) \times E\left(C P I_{t i k}\right)
$$

Como

$$
\begin{gathered}
E\left(N_{s}\right)=E\left(E\left(N_{s} \mid \lambda_{a 1 a 2}, \beta_{s}\right)\right)=E\left(\lambda_{a_{1} a_{2}} \times \beta_{s}\right) \stackrel{i n d}{=} E\left(\lambda_{a_{1} a_{2}}\right) \times E\left(\beta_{s}\right) \\
E\left(N_{s}\right)=\frac{\varphi_{a_{1} a_{2}}}{\vartheta_{a_{1} a_{2}}} \times \frac{\tau_{s}}{\tau_{0}} .
\end{gathered}
$$

Então,

$$
E\left(\sup \text { Gasto }_{s_{a d_{i}}}\right)=C P C_{s_{a d_{i}}} \times C T R_{s_{a d_{i}}} \times \frac{\varphi_{a_{1} a_{2}}}{\vartheta_{a_{1} a_{2}}} \times \frac{\tau_{s}}{\tau_{0}}
$$

O gasto esperado do anúncio $i$ na configuração $s$ vai depender da escolha do $C P C M_{s}$ através do $C P C_{s_{a d_{i}}}$ e do $C T R_{s_{a d_{i}}}$. Ele também vai depender do anúncio escolhido através do $C T R_{s_{a d_{i}}}$ e da configuração $s$.

Além disso, como $E\left(\sup\right.$ Gasto $\left._{s_{a d_{i}}}\right)$ é o investimento esperado necessário para se participar de todas as buscas na configuração $s$. Note que o valor máximo gasto é não decrescente com o aumento do budget, então avaliando-se o valor inverso no qual $E\left(\sup G a s t s_{a_{a_{i}}}\right)=B_{s_{a d_{i}}}$, onde $B_{s_{a d_{i}}}$ é o valor alocado para o anúncio $i$ na configuração $s$. Então, tem-se que

$$
B_{s_{a d_{i}}}=E\left(I_{s_{a d_{i}}}\right) \times E\left(C P I_{s_{a d_{i}}}\right)
$$

Portanto,

$$
E\left(I_{s_{a d_{i}}}\right)=\frac{B_{s_{a d_{i}}}}{E\left(C P I_{s_{a d_{i}}}\right)}
$$




\subsection{Obtendo o Lucro Esperado}

Seja $Y_{s_{a d_{i} l d_{j}}}$ o lucro esperado obtido na configuração $s$ do anúncio $i$ e da landing Page $j$. Então, tem-se que:

$$
Y_{s_{a d_{i} l d_{j}}}=E\left(\text { Ganho }_{s_{a d_{i} l d_{j}}}-\text { Gasto }_{s_{a d_{i}}}\right)=E\left(\text { Ganho }_{s_{a d_{i} l d_{j}}}\right)-E\left(\text { Gasto }_{s_{a d_{i}}}\right)
$$

Conforme foi visto na seção 4.4.2, tem-se que:

$$
\begin{gathered}
E\left(\operatorname{Ganho}_{s_{a d_{i} l d_{j}}}\right)=L_{a_{1}} \times C T R_{s_{a d_{i}}} \times\left(\frac{\nu_{s_{a d_{i} l d_{j}}}}{\nu_{s_{a d_{i} l d_{j}}}+\kappa_{s_{a d_{i} l d_{j}}}}\right) \times E\left(I_{s_{a d_{i}}}\right) \\
E\left(\text { Gasto }_{s_{a d_{i}}}\right)=C P C_{s_{a d_{i}}} \times C T R_{s_{a d_{i}}} \times E\left(I_{s_{a d_{i}}}\right)
\end{gathered}
$$

utilizando o resultado encontrado na seção 4.4.3, tem-se que

$$
\begin{aligned}
& Y_{s_{a d_{i} l d_{j}}}=E\left(\text { Ganho }_{s_{a d_{i} l d_{j}}}\right)-E\left(\text { Gasto }_{s_{a d_{i}}}\right) \\
& =L_{a_{1}} \times E\left(I_{s_{a d_{i}}}\right) \times C T R_{s_{a d_{i}}} \times\left(\frac{\nu_{s_{a d_{i} l d_{j}}}}{\nu_{s_{a d_{i} l d_{j}}}+\kappa_{s_{a d_{i} l d_{j}}}}\right)-C P C_{s_{a d_{i}}} \times E\left(I_{s_{a d_{i}}}\right) \times C T R_{s_{a d_{i}}}
\end{aligned}
$$

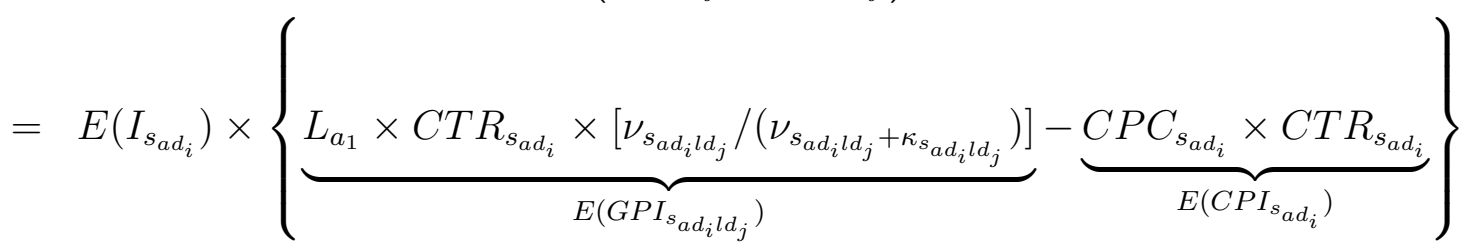

$$
\begin{aligned}
& =\frac{B_{s_{a d_{i}}}}{E\left(C P I_{s_{a d_{i}}}\right)} \times\left[E\left(G P I_{s_{a d_{i} l d_{j}}}\right)-E\left(C P I_{s_{a d_{i}}}\right)\right] \\
& =B_{s_{a d_{i}}} \times \underbrace{\left[\frac{E\left(G P I_{s_{a d_{i} l d_{j}}}\right)-E\left(C P I_{s_{a d_{i}}}\right)}{E\left(C P I_{s_{a d_{i}}}\right)}\right]}_{R O A S_{s_{a d_{i} l d_{j}}}} \\
& Y_{s_{a d_{i} l d_{j}}}=B_{s_{a d_{i}}} \times R O A S_{s_{a d_{i} l d_{j}}},
\end{aligned}
$$

onde

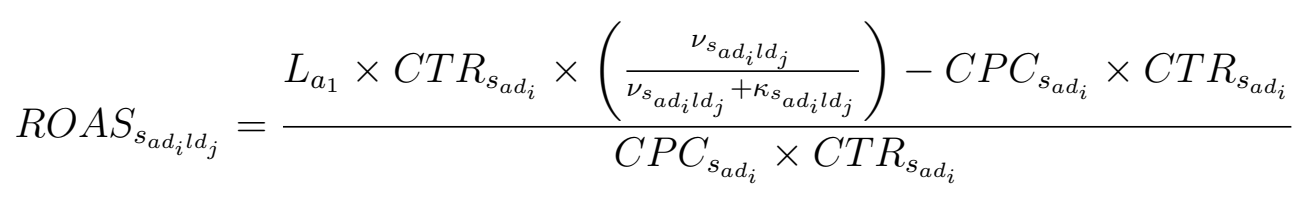


Simplificando a última expressão, obtemos

$$
R O A S_{s_{a d_{i} l d_{j}}}=\frac{L_{a 1} \times\left(\frac{\nu_{s_{a d_{i} l d_{j}}}}{\nu_{s_{a d_{i} l d_{j}}+\kappa_{s_{a d_{i} l d_{j}}}}}\right)-C P C_{s_{a d_{i}}}}{C P C_{s_{a d_{i}}}}
$$

Note que o lucro esperado $Y_{s_{a d_{i} l d_{j}}}$ é valor investido (Budget) multiplicado pelo valor esperado do ROAS. Conforme foi apresentado no capítulo 2, tradicionalmente as campanhas já são avaliadas em função do $R O A S$, entretanto aqui será utilizado a esperança da variável aleatória $R O A S$ que dependera diretamente da configuração $s$ e das decisões do agente decisor. No capitulo 5, será explicado os beneficios de se utilizar está abordagem em vez da tradicional. Vale ressaltar que mesmo o lucro esperado sendo função do ROAS, há um valor máximo esperado de investimento que é igual a $E\left(\sup\right.$ Gasto $\left._{s_{a d_{i}}}\right)$.

\subsection{Restrição do Espaço de Decisão}

Devido a grande quantidade de configurações que determinam o espaço de decisão, é muito importante restringir o domínio das decisões de modo que se descarte aquelas inadmissíveis e com isto agilize as simulações do método de Monte Carlo necessário para solucionar o problema de otimização.

Foi visto anteriormente que o investimento máximo utilizado na configuração $s$ do anúncio $i$ é de $E\left(\sup\right.$ Gasto $\left._{s_{a d_{i}}}\right)$. Então,

$$
B_{s_{a d_{i}}} \in\left[0, C P C_{s_{a d_{i}}} \times C T R_{s_{a d_{i}}} \times \frac{\varphi_{a_{1} a_{2}}}{\vartheta_{a_{1} a_{2}}} \times \frac{\tau_{s}}{\tau_{0}}\right]
$$

Note que conforme o lance máximo por clique aumenta, o suporte do investimento também aumenta. Isto já era esperado, pois se o lance aumenta, consequentemente o valor pago por clique também aumenta, fazendo com que seja necessário um investimento maior para se participar de todos leilões. Observe também que, se o lance máximo for zero, automaticamente o custo por clique será zero e neste caso não precisa de investimento algum nesta configuração.

Analisando o domínio do $C P C M_{s}$, para que o lucro esperado seja positivo, devemos ter que 


$$
\begin{gathered}
E\left(\text { Ganho }_{s_{a d_{i} l d_{j}}}\right) \geq E\left(\text { Gasto }_{s_{a d_{i}}}\right) \\
L_{a_{1}} \times E\left(I_{s_{a d_{i}}}\right) \times C T R_{s_{a d_{i}}} \times\left(\frac{\nu_{s_{a d_{i} l d_{j}}}}{\nu_{s_{a d_{i} l d_{j}}}+\kappa_{s_{a d_{i} l d_{j}}}}\right) \geq C P C_{s_{a d_{i}}} \times E\left(I_{s_{a d_{i}}}\right) \times C T R_{s_{a d_{i}}} \\
L_{a_{1}} \times\left(\frac{\nu_{s_{a d_{i} l d_{j}}}}{\nu_{s_{a d_{i} l d_{j}}}+\kappa_{s_{a d_{i} l d_{j}}}}\right) \geq C P C_{s_{a d_{i}}}
\end{gathered}
$$

Se a desigualdade acima for verdadeira para qualquer $C P C_{s_{a d_{i}}}$, então necessariamente deve valer para o $C P C M_{s}$ que é supremo do custo por clique. Portanto

$$
C P C M_{s} \in\left[0, L_{a_{1}} \times\left(\frac{\nu_{s_{a d_{i} l d_{j}}}}{\nu_{s_{a d_{i} l d_{j}}}+\kappa_{s_{a d_{i} l d_{j}}}}\right)\right]
$$

Quando o lance máximo por clique é muito baixo, o anúncio deixa de aparecer na primeira página. Devido a isto, mesmo que houvesse um investimento suficiente para participar dos leilões, o anúncio participaria de poucos leilões, isto porque dificilmente um usuário navega da segunda página em diante página da SERP. Geralmente, quando um usuário não encontra o que está buscando na primeira página ele refaz a pesquisa.

Além da restrição acima, é importante que o anúncio apareça na primeira página da SERP, pois se um usuário não encontra o que está procurando na primeira página com os anúncios e mais os 10 resultados orgânicos então provavelmente esteja fazendo uma busca com a palavra-chave errada e deve em seguida refazer sua busca com outra palavra-chave diferente. Devido a isto, os lances serão restritos a valores de $C P C M$ necessários para estar na primeira página. Assim,

$$
C P C M_{s} \in\{0\} \cup\left[\iota_{s}, L_{a_{1}} \times\left(\frac{\nu_{s_{a d_{i} l d_{j}}}}{\nu_{s_{a d_{i} l d_{j}}}+\kappa_{s_{a d_{i} l d_{j}}}}\right)\right]
$$

onde $\iota_{s}$ representa o lance máximo por clique necessário para o anúncio aparecer na primeira página da SERP. A forma de obter uma estimativa do $\iota_{s}$ será mostrada no próximo capítulo na seção de procedimento Bayesiano. 


\subsection{A Existência de um $C P C M_{s}$ que maximiza o Lucro}

\section{Esperado $s$}

Foi mostrado na seção 4.7 que o lucro esperado é função do investimento e do ROAS. Também foi mostrado que o valor máximo de investimento está limitado superiormente. Por causa disto, esta seção pretende evidenciar que existe um valor do $C P C M_{s}$ que maximiza o lucro esperado. Na seção anterior, foi mostrado que o valor investido é no máximo $C P C_{s_{a d_{i}}} \times$

$C T R_{s_{a d_{i}}} \times \frac{\varphi_{a_{1} a_{2}}}{\vartheta_{a_{1} a_{2}}} \times \frac{\tau_{s}}{\tau_{0}}$, que depende da escolha do $C P C M_{s}$ através do $C P C_{s_{a d_{i}}}$ e $C T R_{s_{a d_{i}}}$ que são funções da escolha do $C P C M_{s}$. Como foi mencionado anteriormente, este valor máximo de investimento é uma função não decrescente em relação a decisão $C P C M_{s}$. Assim, pode-se escrever este valor da seguinte forma:

$$
\begin{aligned}
\operatorname{Max}\left(B_{s}^{*}\right) & =C P C_{s_{a d_{i}}} \times C T R_{s_{a d_{i}}} \times \frac{\varphi_{a_{1} a_{2}}}{\vartheta_{a_{1} a_{2}}} \times \frac{\tau_{s}}{\tau_{0}} \\
& =\underbrace{k}_{\text {Constante }} \times C P C_{s_{a d_{i}}} \times C T R_{s_{a d_{i}}} \\
& =k \times f\left(I Q_{s_{a_{i} l_{j} j}} \times C P C M_{s}\right)
\end{aligned}
$$

onde $I Q_{s_{a d_{i} l d_{j}}}$ representa o índice de qualidade na configuração $s$, do anúncio $i$ e da Landing Page $j$.

Conforme aumenta-se o $C P C M_{s}$ o anúncio fica melhor classificado e, consequentemente, recebe mais cliques e, necessita de um investimento maior para concorrer a todos os leilões. Para exemplificar este comportamento, a Figura 4.2 apresenta os investimentos máximos obtidos do planejador de palavras chaves do google que mostra que o valor investido aumenta conforme se aumenta o CPCM.

Agora, é preciso analisar o comportamento do ROAS em relação ao aumento do $C P C M$. Conforme foi mostrado anteriormente,

$$
R O A S_{s_{a d_{i} l d_{j}}}=\frac{L_{a_{1}} \times\left(\frac{\nu_{s_{a d_{i} l d_{j}}}}{\nu_{s_{a d_{i} l d_{j}}}+\kappa_{s_{a d_{i} l d_{j}}}}\right)-C P C_{s_{a d_{i}}}}{C P C_{s_{a d_{i}}}}
$$




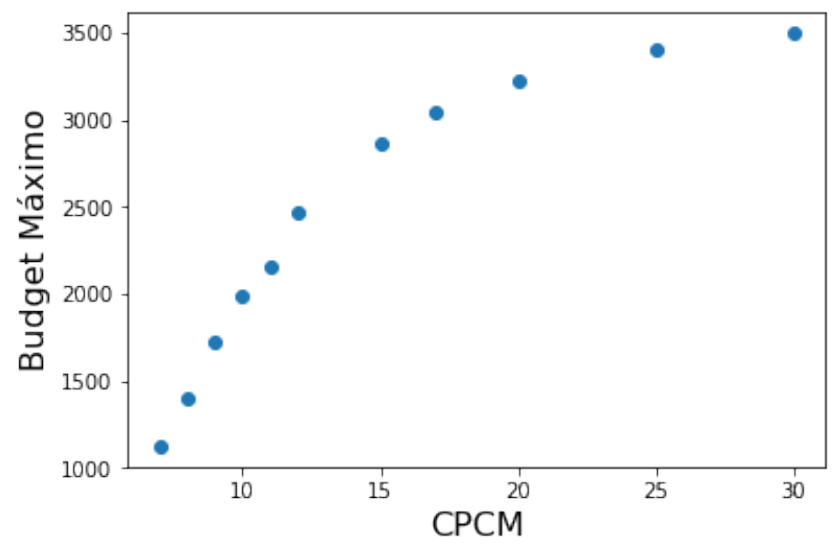

Figura 4.2: Investimento máximo por $C P C M$

$$
\begin{gathered}
R O A S_{s_{a d_{i} l d_{j}}}=\frac{L_{a_{1}} \times\left(\frac{\nu_{s_{a d_{i} l d_{j}}}}{\left.\nu_{a_{a d_{i} l d_{j}}+\kappa_{a_{a d_{i} l d_{j}}}}\right)}-1\right.}{C P C_{s_{a d_{i}}}}-1 \\
R O A S_{s_{a d_{i} l d_{j}}}=\frac{k}{g\left(I Q_{s_{a d_{i} l d_{j}}}, C P C M_{s}\right)}-1, \text { com } k \text { constante }
\end{gathered}
$$

Quanto maior é o CPCM, mais alto vai ser o CPC, e, portanto, menor será o ROAS. Isto é esperado porque quanto mais alto o lance por um clique maior será o valor pago e, consequentemente, menor será o retorno sobre gasto em publicidade (ROAS), o que fica evidenciado pela Figura 4.3 que mostra o decrescimento do ROAS conforme aumenta-se o CPCM.

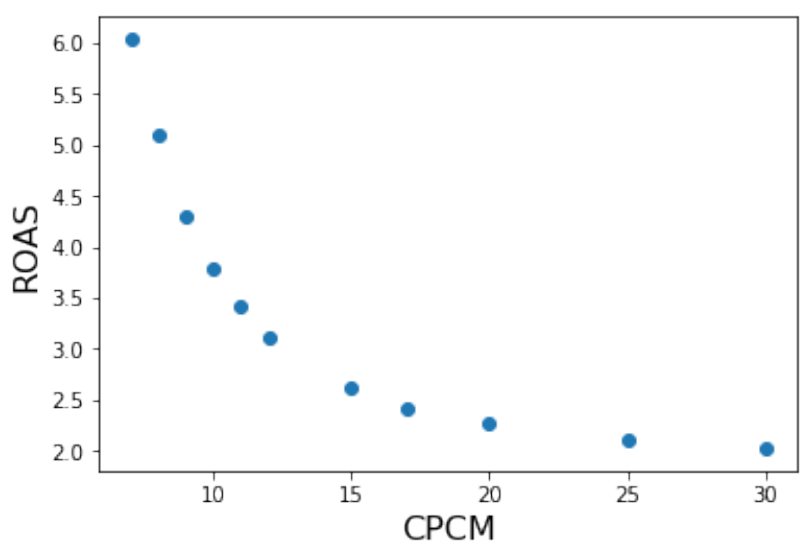

Figura 4.3: $R O A S$ por $C P C M$

Assim, é possível supor que por causa da formas das curvas há um ponto de máximo. 


\subsubsection{Algoritmo para Encontrar o CPCM Máximo}

Neste momento, é importante encontrar uma forma de determinar o valor do $C P C M$ que faz com que o lucro esperado seja máximo. Então, será construído o algoritmo do método de exploração estocástica para achar o valor do $C P C M$ que maximiza o lucro esperado para uma configuração $s$, do anúncio $i$ e da landing page $j$.

\section{Lógica do Programa}

Na figura B.1 no apêndice B está um código comentado de uma função que vai calcular o $C P C M$ para uma determinada configuração $s$.

\subsubsection{Obtendo a Solução Ótima}

A otimização será realiza em três passos:

Primeira etapa: Será encontrado o $C P C M$ ótimo e o Budget máximo para todas as configurações $s$ para cada anúncio e landing page.

Segundo etapa: Será escolhido o melhor anúncio e landing page para cada $s \in S$ utilizando o principio da utilidade esperada e os valores encontrados no primeiro passo.

Terceiro etapa: Será investido o budget entre todas as configurações $s$ de modo a maximizar o lucro esperado final.

O leitor pode se perguntar se essa estratégia realmente conduz a um máximo quando seleciona-se inicialmente os anúncios e landing page para depois repartir o budget, não iremos demostrar, mas ao se selecionar o melhor anúncio e página de destino automaticamente estão sendo privilegiados combinações com maiores $C T R$ e taxa de conversão, então qualquer combinação entre anúncio e página de destino tera um rendimento no máximo igual ao do melhor anúncio e landing page.

\section{Encontrando o $C P C M_{s_{a d_{i} l d_{j}}}$ Ótimo}

Para resolver este problema, será considerado que toda combinação de anúncio e de página de destino recebe todas as impressões disponíveis e, a partir disto, o objetivo é achar o $C P C M_{s}$ que maximiza o lucro esperado da configuração $s$ utilizando o algoritmo da seção 
4.9.1.

\section{Decisão Ótima do Anúncio e da Landing Page}

O objetivo desta seção é, finalmente escolher qual é a melhor combinação entre os anúncios e as landing pages na configuração s. Neste contexto, tem-se que o total de possíveis escolhas para essa combinação é, pelo teorema fundamental da contagem,

\section{\#Anúncios $\times$ \#Landing Pages.}

Conforme visto no terceiro capítulo, a decisão de Bayes é aquela que maximiza a utilidade esperada que, neste caso, como a função utilidade é linear, significa maximizar o lucro esperado.

A metodologia consiste em calcular o lucro esperado para cada $\left(a d_{i} \times l d_{j}\right)$ pertencente ao produto cartesiano do conjunto de Anúncios, $A d_{i}$, com o das Landing Pages, $L d_{j}$, e a solução final será aquela que maximizar o lucro esperado.

\section{Alocando o Budget entre as Configurações $s$}

Neste momento, o agente decisor deve alocar o Budget entre todas as configurações disponíveis. Lembramos que já foram escolhidos o anúncio $a d_{i}^{*}$, a langing page $l d_{j}^{*}$ e o $C P C M_{s_{a d_{i}^{*} l d_{j}^{*}}}$ para todas as configurações $s \in S$.

Portanto, deve-se escolher os $B_{s}$ de modo a maximizar a utilidade esperada. Portanto, a decisão ótima é aquela que maximiza o lucro esperado total, ou seja

$$
Y=\sum_{s \in S} Y_{s_{a d_{i}^{*} l d_{j}^{*}}}=\sum_{s \in S} R O A S_{s_{a d_{i}^{*} l d_{j}^{*}}}\left(C P C M_{s_{a d_{i}^{*} l d_{j}^{*}}}\right) \times B_{s}
$$

com as restrições $B_{s} \geq 0$ e $B_{s} \leq B_{\max }\left(C P C M_{s_{a d_{i}^{*} l d_{j}^{*}}}\right)$, onde

$$
B_{\max }\left(C P C M_{s_{a d_{i}^{*} l d_{j}^{*}}}\right)=C P C_{s_{a d_{i}}}\left(C P C M_{s_{a d_{i}^{*} l d_{j}^{*}}}\right) \times C T R_{s_{a d_{i}}}\left(C P C M_{s_{a d_{i}^{*} l d_{j}^{*}}}\right) \times \frac{\varphi_{a_{1} a_{2}}}{\vartheta_{a_{1} a_{2}}} \times \frac{\tau_{s}}{\tau_{0}}
$$

com

$$
\sum_{s \in S} B_{s}=B
$$


Note que, neste momento, tanto o $B_{\max }\left(C P C M_{s_{a d_{i}^{*} l d_{j}^{*}}}\right)$ quanto o $R O A S_{s_{a d_{i}^{*} l d_{j}^{*}}}\left(C P C M_{s_{a d_{i}^{*} l d_{j}^{*}}}\right)$ são constantes, pois dependem apenas da decisão $C P C M_{s_{a d_{i}^{*} d_{j}^{*}}}$ já determinada. Então, este problema se resume nesse ponto a um problema de programação linear que pode ser resolvido pelo método simplex. Entretanto como, neste caso, o ROAS representa retorno e se deseja otimizar uma função soma, basta que se faça o seguinte procedimento: ordenar as configurações segundo o ROAS e, em seguida, alocar o Budget sucessivamente para as melhores configurações (de maiores ROAS) segundo, respeitando os valores máximos de budget das configurações.

Por exemplo, vamos supor que em uma campanha se tenha um Budget de $\mathrm{R} \$ 1000,00$ reais e que já foi escolhido o melhor anúncio, página de destino, assim como, o CPCM para todas as configurações. Os valores ótimos e os máximos, $B_{s}^{*}$ e $B_{\max }$ respectivamente, são apresentados para as configurações ordenadas segundo o ROAS na Tabela 4.3.

\begin{tabular}{cccc}
\hline ROAS & $B_{\max }$ & $\mathrm{s}$ & $\mathrm{B}^{*}$ \\
\hline 10 & 50 & 7 & 50 \\
5 & 200 & 2 & 200 \\
3 & 500 & 500 & 500 \\
2 & 2000 & 270 & 250 \\
1 & 5000 & 63 & 0 \\
$\vdots$ & $\vdots$ & $\vdots$ & $\vdots$ \\
0.01 & 300 & 58 & 0 \\
\hline
\end{tabular}

Tabela 4.3: Alocando o Budget na campanha

Assim, na primeira linha que corresponde a configuração $s=7$ que possui o ROAS igual a 10 que é o maior, então será investido o máximo do budget possível nesta configuração que é 50 reais. Sobrando $\mathrm{R} \$ 950,00$ que deve ser investido. O próximo maior ROAS é a configuração $s=2$, segunda linha que possui um ROAS de 5 então será investido $\mathrm{R} \$ 200,00$ que o máximo do budget que está configuração aceita. Ficando ainda livre $\mathrm{R} \$ 750,00$ para ser aplicado. Do mesmo modo dos passos anteriores será investido $\mathrm{R} \$ 500,00$ na configuração $s=500$ e ainda continua acessível $\mathrm{R} \$ 250,00$ do budget. Seguindo o procedimento antecedentes o maior ROAS é o da posição $s=270$ que pode aplicado até $\mathrm{R} \$ 2.000,00$ entretanto como só há disponível $\mathrm{R} \$ 250,00$ será investido integralmente nesta opção. Então o restante das demais configurações que não receberam budget até este momento não receberão mais investimentos e o lucro esperado final será de 


$$
Y=50 \times 10+200 \times 5+500 \times 3+250 \times 2=R \$ 3.500,00
$$

Observe que quando é escolhido o melhor anúncio, páginas de destino e o $C P C M$, a decisão de como o budget será aplicado é bastante simples. Além disso, este método corrobora com o que já feito tipicamente ao se analisar uma campanha, entretanto aqui será utilizado o ROAS calculado com valores esperados enquanto tradicionalmente se utiliza-se históricos da campanha.

O processo de otimização do budget é similar ao utilizado ao se montar o teste mais poderoso com o Lema de Neyman-Pearson, no qual tem a restrição do ser de nível $\alpha$ e é ordenado o razão de verossimilhança e vai se dividindo a significância até atingir o nível $\alpha$ conforme é mostrado na equação abaixo.

A otimização do budget é similar a realizada para se obter o teste mais poderoso através do lema de Neyman-Pearson, lá o objetivo é encontrar o teste mais poderoso de nível $\alpha$, então se ordena a razão de verossimilhança e a soma até a mesma ser igual a $\alpha$. Ou seja:

$$
\operatorname{Max} \sum_{x \in \varphi^{-1}(1)} R V(x) \times \varphi(x) \times P\left(X=x \mid \theta_{0}\right)
$$

restrito a $\varphi(x) \leq 1, \forall x \in X$ e $\sum \varphi(x) \times P\left(X=x \mid \theta_{0}\right) \leq \alpha$

No marketing digital

$$
\operatorname{Max} \sum_{s \in S} R O A S_{s} \times B_{s}
$$

restrito a $B_{s} \leq B_{\max }$ e $\sum B_{s} \leq B$ 


\section{Capítulo 5}

\section{Procedimento Bayesiano e Simulações}

Um dos motivos para este trabalho utilizar a Teoria da Decisão Bayesiana é que há várias informações que podem ser utilizadas para a construção de distribuições a priori. É possível utilizar como fonte de informação a priori para um campanha no google ads o planejador de palavras-chave, a API (Application Programming Interface) do google ads, outras campanhas similares e a experiência do anunciante. Além disso, após observar a performance da campanha por um período, pode-se utilizar estes dados para atualizar a incerteza sobre os parâmetros do modelo de interesse através da operação bayesiana, resultando na distribuição a posteriori.

Este capítulo pretende mostrar como foi escolhida a distribuição a priori de cada parâmetro e, a partir dela, como foi calculada a distribuição posteriori. Pretende-se também simular uma campanha e comparar o método proposto por este trabalho com o que tradicionalmente utilizado para avaliar campanhas.

\subsection{Procedimento Bayesiano}

O google disponibiliza algumas ferramentas que auxiliam anunciantes a montarem sua campanha, essas ferramentas são: o planejador de palavras-chave e a API do google ads. Essas ferramentas propiciam aos anunciantes certas estatísticas que auxiliam na criação das campanhas.

Através dessas estatísticas, pode-se construir as distribuições a priori e otimizar uma campanha. Após se observar os resultados da campanha, pode-se obter as distribuições a 
posteriori que serão utilizadas na obtenção de uma configuração ótima.

No Apêndice A, há uma lista das classes conjugadas que serão utilizadas neste capítulo. Basicamente, uma classe de distribuições é conjugada se para um modelo especifico a distribuição a priori e a posteriori pertencem a essa mesma família de distribuições.

Os parâmetros incertos que serão estimados nesta seção são média de buscas mensais $\left(\lambda_{a_{1} a_{2}}\right)$; percentual de buscas por dispositivo, dia da semana, horários $\left(\beta_{a_{1} a_{2} P_{1} P_{2} P_{3}}\right)$; taxa de conversão $\left(C R_{s_{a d_{i} l d_{j}}}\right)$ e lance mínimo da primeira página $\left(\iota_{s}\right)$. Pode-se considerar que a taxa de conversão é independente das demais, pois representa o comportamento dos usuários ao entrar na página de destino, do mesmo modo pode ser considerado que o lance mínimo para estar na primeira página é algo que não vai depender da quantidade de buscas e sim do google e da concorrência por determinada palavra-chave, do mesmo modo vamos supor que $\lambda_{a_{1} a_{2}}$ e $\beta_{a_{1} a_{2} P_{1} P_{2} P_{3}}$ são independentes pois o $\lambda$ representa a medias das buas e o $\beta$ é a percetual destas médias referente as configurações $s$. Sabe-se que a estimação da distribuição para variáveis aleatórias independentes pode ser feita marginalmente.

A seguir será desmembrado o método de estimação utilizado para encontrar as distribuições a posteriori utilizadas para resolver o problema de decisão.

\subsubsection{Elicitação de Prioris}

\section{Média de Buscas Mensais}

Através do planejador de palavra-chave e da API do google ads, é possível obter a estimativa da média mensal de buscas para um determinado mês para uma palavra-chave $a_{1}$ na cidade $a_{2}$. Esta estimativa será utilizada para construir uma distribuição a priori informativa para $\lambda_{a_{1} a_{2}}$. Conforme foi descrito, anteriormente para uma palavra chave $a_{1}$ na cidade $a_{2}$ :

$$
N_{a_{1} a_{2}} \mid \lambda_{a_{1} a_{2}} \sim \operatorname{Poisson}\left(\lambda_{a_{1} a_{2}}\right)
$$

com

$$
\lambda_{a_{1} a_{2}} \sim \operatorname{Gama}\left(\varphi_{a_{1} a_{2}}, \vartheta_{a_{1} a_{2}}\right)
$$

Seja $\bar{N}_{a_{1} a_{2} 0}$ a média de buscas para a palavra-chave $a_{1}$ na cidade $a_{2}$ para o mês corres- 
pondente obtida no planejador de palavra-chave ou na API. Então, será construído uma distribuição a priori gama para $\lambda_{a_{1} a_{2}}$ com parâmetros $\varphi_{a_{1} a_{2}}$ e $\vartheta_{a_{1} a_{2}}$ iguais a $\bar{N}_{a_{1} a_{2} 0}$ e a 1 respectivamente. Entretanto, se a quantidade média for nula, será utilizada priori Exponencial com parâmetro 1, ou seja Gama com parâmetros 1 e 1.

Para exemplificar, foi retirada do planejador de palavras-chave as quantidades de buscas médias para as palavras-chave "A"e "B"(as palavras-chave foram omitidas por simplificação) para algumas cidades paulistas (Tabela 5.1).

\begin{tabular}{l|rr}
\hline Cidade & Palavra Chave "A" & Palavra Chave "B" \\
\hline São Paulo & 2666,24 & 2730,12 \\
Guarulhos & 249,63 & 148,09 \\
São Bernardo do Campo & 129,89 & 174,72 \\
Mauá & 125,84 & 135,23 \\
Santo André & 114,24 & 138,75 \\
Carapicuíba & 110,01 & 124,9 \\
Barueri & 97,6 & 85,6 \\
Franco da Rocha & 87,5 & 83,91 \\
Osasco & 86,89 & 26,59 \\
Diadema & 38,75 & 35,76 \\
São Caetano do Sul & 32,65 & 15,38 \\
Santana de Parnaíba & 21,68 & 21,82 \\
Mairiporã & 10,8 & 10,99 \\
Caieiras & 0 & 4,33 \\
\hline
\end{tabular}

Tabela 5.1: Quantidade média de buscas por palavra chave em algumas cidades paulista

A partir desses valores, pode-se construir as distribuições a priori de $\lambda_{a_{1} a_{2}}$ para todas as cidades e palavras-chave "A"e "B". A tabela 5.1 apresenta os valores de $\bar{N}_{a_{1} a_{2} 0}$. A Tabela 5.2 apresenta as distribuições a priori para $\lambda_{a_{1} a_{2}}$ para todas as palavras chave $a_{1}$ e cidades $a_{2}$ da Tabela 5.1.

As Figuras 5.1 e 5.2 mostram as distribuição a priori de $\lambda_{a_{1} a_{2}}$ para as cidades de São Paulo e Caieiras, para as palavras-chave "A"e "B". As distribuições a priori da cidade de São Paulo são mais simétricas e possuem uma grande variância, enquanto que as prioris para Caeiras são assimétricas e bem concentradas. Uma observação muito importante é que quando uma palavra-chave possuir, em média, 0 busca mensal, como no caso da Figura 5.2 (Caieras) da palavra chave "A", é atribuído uma priori exponencial para não colocar uma distribuição degenerada na priori. Ao escolher uma exponencial como priori faz-se com que a a variância seja muito maior e se dá mais peso para dados do que para a distribuição à 


\begin{tabular}{l|rr}
\hline Cidade & Palavra Chave "A" & Palavra Chave "B" \\
\hline São Paulo & $\operatorname{Gamma}(2666.24,1)$ & $\operatorname{Gamma}(2730.12,1)$ \\
Guarulhos & $\operatorname{Gamma}(249.63,1)$ & $\operatorname{Gamma}(148.09,1)$ \\
São Bernardo do Campo & $\operatorname{Gamma}(129.89,1)$ & $\operatorname{Gamma}(174.72,1)$ \\
Mauá & $\operatorname{Gamma}(125.84,1)$ & $\operatorname{Gamma}(135.23,1)$ \\
Santo André & $\operatorname{Gamma}(114.24,1)$ & $\operatorname{Gamma}(138.75,1)$ \\
Carapicuíba & $\operatorname{Gamma}(110.01,1)$ & $\operatorname{Gamma}(124.90,1)$ \\
Barueri & $\operatorname{Gamma}(97.60,1)$ & $\operatorname{Gamma}(85.60,1)$ \\
Franco da Rocha & $\operatorname{Gamma}(87.50,1)$ & $\operatorname{Gamma}(83.91,1)$ \\
Osasco & $\operatorname{Gamma}(38.89,1)$ & $\operatorname{Gamma}(26.59,1)$ \\
Diadema & $\operatorname{Gamma}(32.65,1)$ & $\operatorname{Gamma}(35.76,1)$ \\
São Caetano do Sul & $\operatorname{Gamma}(21.68,1)$ & $\operatorname{Gamma}(15.38,1)$ \\
Santana de Parnaíba & $\operatorname{Gamma}(10.80,1)$ & $\operatorname{Gamma}(10.99,1)$ \\
Mairiporã & $\operatorname{Gamma}(1,1)$ & $\operatorname{Gamma}(4.33,1)$ \\
Caieiras & &
\end{tabular}

Tabela 5.2: Priori por palavra chave e cidade

priori.
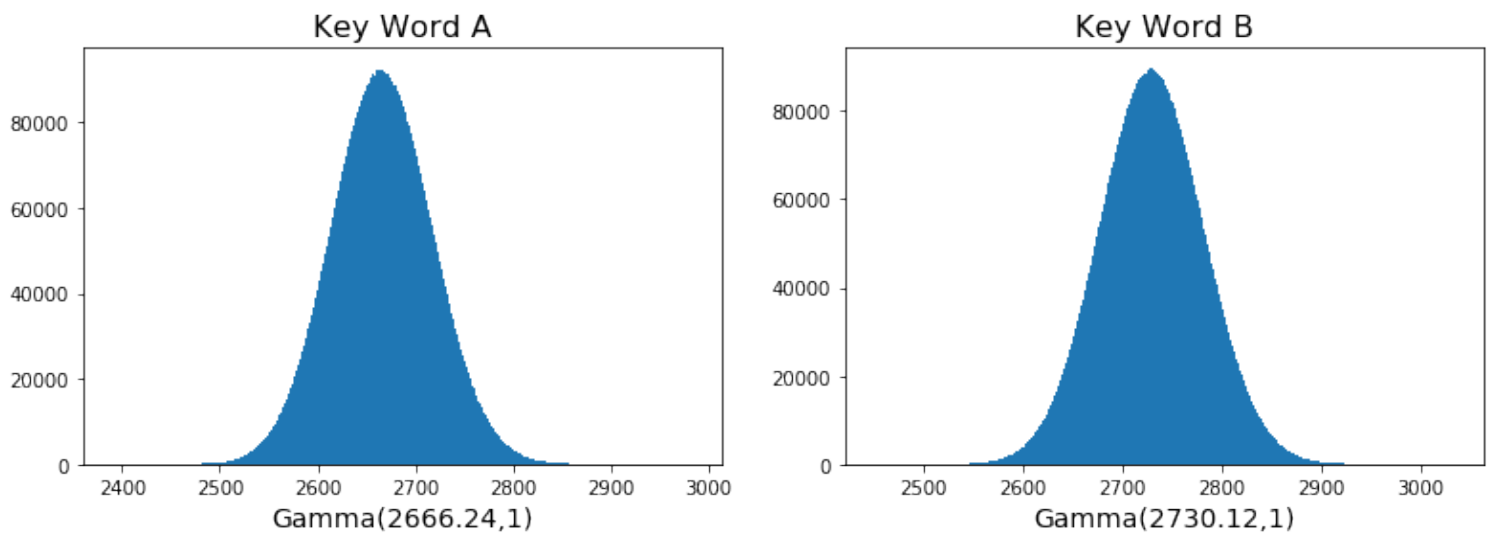

Figura 5.1: Distribuições a Priori de São Paulo

A priori foi determinada deste jeito porque tanto o planejador de palavras-chave quanto a API não fornecem estimativas da variância nem do desvio padrão para a quantidade de buscas. Tentou-se escolher prioris com um variância alta e que não fossem similares a distribuição exponencial que concentra uma massa de probabilidade próximo do zero que seria algo fora do que acontece em campanhas PPC.

\section{Percentual de buscas por Dispositivo, Dia da Semana, Horários}

Observe que fixando a palavra-chave $a_{1}$ e a cidade $a_{2}$ a quantidade de buscas por dispositivo, dia da semana e horário formam uma partição da quantidade de buscas fixados $a_{1}$ e $a_{2}$. Então, será utilizada uma distribuição de Dirichilet como priori para $\beta_{a_{1} a_{2} P_{1} P_{2} P_{3}}$. 

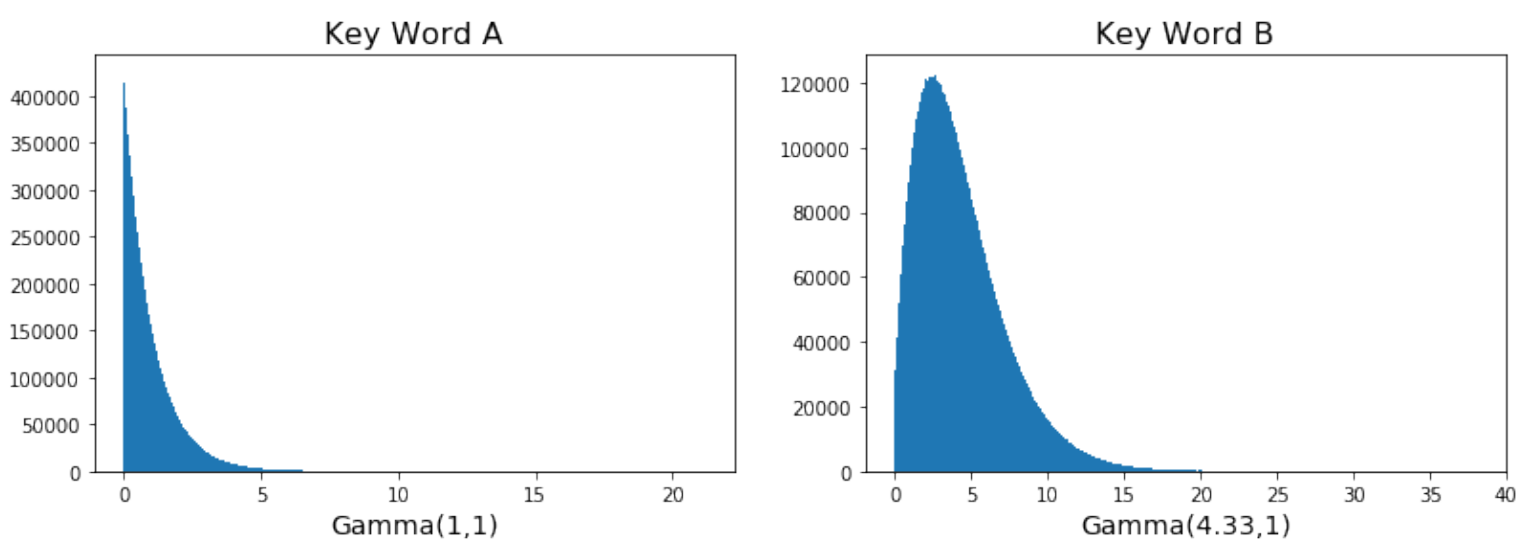

Figura 5.2: Distribuições a Priori de Caieiras

Pode-se construir uma distribuição a priori informativa utilizando dados de campanhas similares, mas será utilizado aqui uma uniforme no correspondente simplex, ou seja, a quantidade de buscas se distribuem uniformemente nas partições $\# P_{1} \times \# P_{2} \times \# P_{3}$. Assim,

$$
\beta_{a_{1} a_{2} P_{1} P_{2} P_{3}} \sim \text { Dirichilet } \underbrace{\left(\frac{1}{\# P_{1} \times \# P_{2} \times \# P_{3}}, \ldots, \frac{1}{\# P_{1} \times \# P_{2} \times \# P_{3}}\right)}_{\# P_{1} \times \# P_{2} \times \# P_{3}+1}
$$

onde

$$
\beta_{s} \sim \operatorname{Beta}\left(\frac{1}{\# P_{1} \times \# P_{2} \times \# P_{3}}, 1\right)
$$

Por exemplo, vamos imaginar que para uma determinada campanha para uma palavrachave $a_{1}$ e cidade $a_{2}$ onde serão utilizados dois dispositivo, os 7 dias da semana e 24 horas, ou seja, há 336 partições a distribuição a priori será:

$$
\beta_{a_{1} a_{2} P_{1} P_{2} P_{3}} \sim \text { Dirichilet } \underbrace{\left(\frac{1}{336}, \ldots, \frac{1}{336}\right)}_{337}
$$

e a distribuição marginal será

$$
\beta_{s} \sim \operatorname{Beta}\left(\frac{1}{336}, 1\right)
$$

O motivo de utilizar a distribuição a priori com está configuração é que cada elemento da partição deve receber o mesmo peso e, além disso, por questões matemáticas foi preferível deixar marginalmente os parâmetros menores ou iguais a um para dar um menor peso para 
priori.

\section{Taxa de Conversão}

Como foi mencionado diversas vezes durante este texto, conversão é um objetivo do site. Se este objetivo é a própria visita ao site, então $C R_{s_{a d_{i} l d_{j}}}=1$. Por outro lado, se o objetivo é uma venda ou o preenchimento de um formulário de solicitações de visita, a correspondente $C R_{s_{a d_{i} l d_{j}}}$ assume valores em $(0,1)$ e pode-se utilizar a seguinte priori.

$$
C R_{s_{a d_{i} l d_{j}}} \sim \operatorname{Beta}\left(\frac{C R_{0}}{1-C R_{0}}, 1\right)
$$

onde $C R_{0}$ é a taxa de conversão média a priori do agente decisor. Por exemplo, se o anunciante acredita que uma campanha possua em geral taxa de conversão igual a 0,20, então a priori será:

$$
C R_{s_{a d_{i} l d_{j}}} \sim \operatorname{Beta}\left(\frac{0.20}{1-0.2}, 1\right) \sim \operatorname{Beta}(0.25,1)
$$

Poderia ser utilizado uma priori do tipo $\operatorname{Beta}\left(C R_{0}, 1-C R_{0}\right)$, entretanto esta distribuição é bimodal e em forma de "U"apresentando massas de probabilidade concentradas próximas do 0 e do 1, entretanto espera-se que a distribuição da taxa de conversão seja unimodal e seja concentrada a valores menores próximos de $C R_{0}$. Também se optou pela priori com parâmetros menores e iguais a um para dar menos peso para a priori.

\section{Lance Mínimo da Primeira Página}

A distribuição a priori para o lance mínimo para a primeira página será $\iota_{s} \sim \operatorname{Pareto}\left(3, \iota_{s 0}\right)$, na qual o valor de $\iota_{s 0}$ será selecionado através do planejador de palavras-chave e representa o lance mínimo a partir do qual o anúncio receberá todas as impressões. Foi escolhido está priori por conveniência matemática e com o primeiro parâmetro da Pareto igual á 3, pois neste caso ela possui os primeiros momentos. Conforme foi mencionado anteriormente, uma campanha no google só tem sentido se o anúncios aparecer na primeira página e por isto é nescessários estimar este parâmetro.

Na Figura 5.3, pode-se ver que a linha azul representa a quantidade de impressões que o 
anúncio receberá se participar de todos os leilões com um determinado $C P C M$. Neste caso, o valor de $\iota_{s 0}=C P C M$ que recebe todas as impressões é $\mathrm{R} \$ 3,96$. Logo a distribuição a priori, neste caso, será $\iota_{s} \sim \operatorname{Pareto}(3,3.96)$.

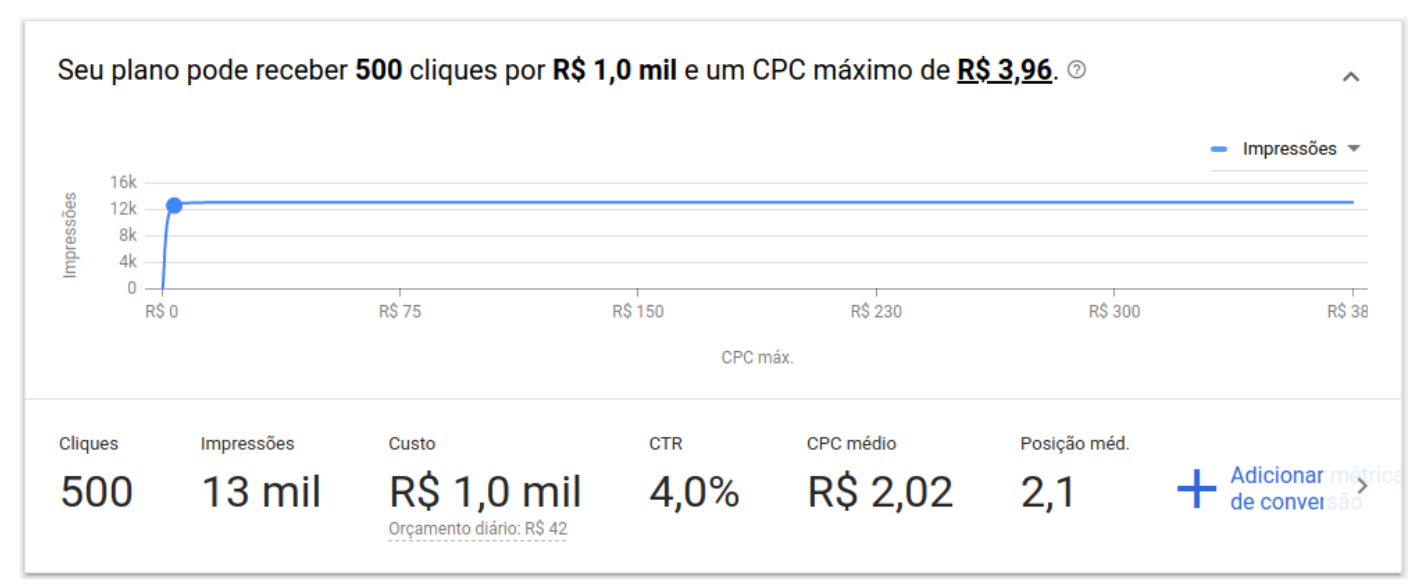

Figura 5.3: Planejador de Palavras-Chave

Na próxima seção, procedemos à determinação da distribuição a posteriori dos parâmetros.

\subsubsection{Encontrando a Distribuição Posteriori}

Foi mencionado na seção 4.3, que, cada usuário clica no anúncio, interage com a página de destino e converte independentemente dos demais usuários. Então por construção, a verossimilhança pode ser fatorada em componentes que dependem de subconjuntos disjuntos do vetor de parâmetros, de modo que a posteriori conjunta pode ser determinada pelas distribuições marginais.

\section{Média de Buscas Mensais}

Para encontrar a distribuição posteriori da quantidade média de buscas mensais, tem-se através do Teorema de Bayes, que

$$
\pi\left(\theta \mid x_{1}, \ldots, x_{n}\right) \propto L(\theta) \pi(\theta)
$$

Neste caso, como a distribuição a priori é uma gama e a observações de $N_{a_{1} a_{2}}$ são Poisson, pode-se utilizar o resultado apresentado na seção A.2 do apêndice. Neste caso, a distribuição 
a posteriori de $\lambda_{a_{1} a_{2}}$ será:

$$
\lambda_{a_{1} a_{2}} \mid N_{a_{1} a_{2}} \sim \operatorname{Gama}\left(a+\sum_{s \in s_{1} s_{2}} N_{s}, b+\left(\# p_{1} \times \# p_{2} \times \# p_{3}\right)\right)
$$

onde, $a$ e $b$ são os parâmetros da distribuição a priori.

Por exemplo, vamos supor uma campanha onde a distribuição priori para uma determinada palavra-chave $a_{1}$ e cidade $a_{2}$ seja $\operatorname{Gama}(100,1)$. Vamos supor que a quantidade de buscas é independente do dispositivo e do horário do dia. Neste caso, o que seria diferente seria apenas a quantidade de buscas por dia. Então, neste contexto, tem-se que

$$
\lambda_{a_{1} a_{2}} \mid N_{a_{1} a_{2}} \sim \operatorname{Gama}\left(100+N_{\text {Seg }}+\ldots+N_{\text {Dom }}, b+7\right)
$$

na qual $N_{\text {Seg }}, N_{\text {Ter }}, N_{Q u a}, N_{Q u i}, N_{\text {Ses }}, N_{S a b}, N_{\text {Dom }}$ representam a quantidade de buscas nos dias da semana.

\section{Percentual de buscas por Dispositivo, Dia da Semana, Horários}

O objetivo desta seção é encontrar a distribuição a posteriori para cada $\beta_{s}$, que representa a proporção de buscas realizadas na configuração $s$ em relação a quantidade de buscas pela palavra-chave $a_{1}$ e cidade $a_{2}$.

Neste caso, será considerado os dados de um período fechado, como uma semana ou um mês, para atualizar a incerteza sobre os $\beta_{s}$. Seja, $\beta_{a_{1} a_{2} P_{1} P_{2} P_{3}}$ o vetor das proporções cuja distribuição a posteriori se pretende encontrar. Então, como

$$
N_{a_{1} a_{2} P_{1} P_{2} P_{3}} \mid N_{a_{1} a_{2}}, \beta_{a_{1} a_{2} P_{1} P_{2} P_{3}} \sim \operatorname{Multinomial}\left(N_{a_{1} a_{2}}, \beta_{a_{1} a_{2} P_{1} P_{2} P_{3}}\right)
$$

$\operatorname{com} \beta_{S} \sim \operatorname{Dirichlet}\left(\tau_{0}, \ldots, \tau_{0}\right)$ com $\tau_{0}$ parâmetro da priori descrito anteriormente. Neste caso, tem-se uma amostra que segue a distribuição multinomial e com a distribuição a priori Dirichlet. Então pode-se utilizar o resultado apresentado na seção A.6 do apêndice. Portanto, a distribuição posteriori de $\beta_{S}$ será

$$
\beta_{a_{1} a_{2} P_{1} P_{2} P_{3}} \mid N_{a_{1} a_{2} P_{1} P_{2} P_{3}}, N_{a_{1} a_{2}} \sim \operatorname{Dirichlet}\left(\tau_{0}+N_{a_{1} a_{2} P_{1} P_{2} P_{3}}\right) .
$$




\section{Taxa de Conversão}

Para encontrar a distribuição a posteriori para a taxa de conversão com amostra Binomial e priori betas vai ser utilizado o resultado apresentado no apêndice A.1. Neste caso, a distribuição a posteriori $C R_{s}$ será

$$
C R_{s_{a d_{i} l d_{j}} \mid} \mid c_{s} \sim \operatorname{Beta}\left(a+c_{s}, b+n-c_{s}\right)
$$

no que $a$ e $b$ são parâmetros da priori especificados anteriormente e $c_{s}$ é a quantidade de conversões.

\section{Lance Mínimo da Primeira Página}

Por conveniência matemática será considerado que quando o anúncio não cai na primeira página é observado um $C P C M_{0}$ que representa uma observação da distribuição $U\left(0, \iota_{s}\right)$. Lembrando que a distribuição a priori é Pareto $\left(3, \iota_{s 0}\right)$. Utilizando o resultado apresentado no A.3 no apêndice, que a posteriori de $\iota_{s}$ será

$$
\iota_{s} \sim \operatorname{Pareto}\left(4, \max \left[\iota_{s 0}, C P C M_{0}\right]\right) .
$$

Onde, para obter a estimativa para o lance mínimo para estar na primeira página, em vez de se utilizar a estimativa utilizando a perda quadrática será utilizado o estimador considerando a perda 0-1 que corresponde a moda da posteriori, que, no caso da distribuição de Pareto do nosso modelo corresponde ao parâmetro $\iota_{s 0}$, a priori, e $\max [b, C P C M]$ no caso da posteriori.

\subsection{Simulações}

Esta seção apresenta uma simulação de um processo de Poisson emulando uma campanha do Google Ads para avaliar o método proposto e comparando com que geralmente é utilizado para avaliar campanhas. 


\subsubsection{Planejamento}

Será simulado uma campanha de um restaurante delivery que funciona somente no final de semana no período da noite e que faz entregas somente para cidade local. O público-alvo da campanha é para pessoas que pesquisam pelo google utilizando o celular. As configurações da campanha são as seguintes:

Dia: sexta, sábado e domingo.

Horários: 18 às 19, 19 às 20, 20 às 21 e 21 às 22.

Palavras-Chave: 'A' e 'B'.

Dispositivos: celular.

Cada palavra-chave representa o mesmo produto e ambas direcionam a mesma página de destino. Serão considerados 3 anúncios para a palavra-chave 'B' e somente um para a 'A', além disso a quantidade de buscas e a taxa de conversão de cada palavra são diferentes. Também será considerado que o Budget disponível é de $\mathrm{R} \$ 800,00$ e um lucro por conversão de $\mathrm{R} \$ 28,00$.

\subsubsection{Metodologias}

Serão comparados duas campanhas, uma utilizando a otimização proposta na capítulo 4 e uma outra que será detalhada em breve. Para ambas as campanhas será dado um período correspondente a 3 meses para gerar dados suficientes para estimar os modelos no caso do capítulo 4 e para gerar estatísticas para ser realizada a otimização tradicional explicada no capítulo 2. Após este período será feito o comparativo entre as campanhas nos próximos 9 meses comparando mês a mês de cada abordagem. O desempenho de ambas as palavraschave, dos anúncios e da landing page será o mesmo para as duas metodologias. O anúncio de maior $C T R$ será o utilizado para a campanha tradicional.

Para fazer essa simulação é necessário que o processo de geração dos dados e da cobrança seja similar ao que acontece naturalmente. Portanto se determina um budget e a campanha fica ativa até o budget acabar ou anúncios aparecer em todas as buscas. Assim, a quantidade 
de buscas é gerada através de um processo de poisson, cada clique é calculado através de um bernoulli que continuará sendo gerada até acabar o budget ou a quantidade de buscas. O valor do clique é calculado atráves de uma normal e a conversão é gerada através de uma bernoulli para cada clique.

\subsubsection{Resultados}

O resultado da simulação utilizando Teoria da Decisão Bayesiana está na Tabela 5.3. Nos nove meses houve 257 conversões, um lucro de $\mathrm{R} \$ 3.436,33$, foi investido $\mathrm{R} \$ 3.763,67$ em campanhas sobrando $\mathrm{R} \$ 3.436,33$ do Budget e o lucro somado ao que não foi utilizado foi de $\mathrm{R} \$ 6.868,66$.

\begin{tabular}{ccccccc}
\hline Mês & Conversões & Gastos & Ganhos & Lucro & Sobra & Lucro+Sobra \\
\hline 1 & 27 & 431,90 & 756,00 & 324,10 & 368,10 & 692,20 \\
2 & 25 & 417,05 & 700,00 & 282,95 & 382,95 & 665,90 \\
3 & 34 & 452,20 & 952,00 & 499,80 & 347,80 & 847,60 \\
4 & 18 & 366,45 & 504,00 & 137,55 & 433,55 & 571,10 \\
5 & 30 & 420,07 & 840,00 & 419,93 & 379,93 & 799,86 \\
6 & 37 & 441,87 & 1036,00 & 594,13 & 358,13 & 952,26 \\
7 & 32 & 402,24 & 896,00 & 493,76 & 397,76 & 891,52 \\
8 & 30 & 393,34 & 840,00 & 446,66 & 406,66 & 853,32 \\
9 & 24 & 438,55 & 672,00 & 233,45 & 361,45 & 594,90 \\
\hline Total & 257 & 3763,67 & 7196,00 & 3432,33 & 3436,33 & 6868,66 \\
\hline
\end{tabular}

Tabela 5.3: Demostrativo da Campanha Utilizando Teoria da Decisão

Os resultados da simulação utilizando o método tradicional está na Tabela 5.4. Nos nove meses houve 353 conversões, um lucro de $\mathrm{R} \$ 2.834,92$, foi investido $\mathrm{R} \$ 7.049,08$ em campanhas sobrando $\mathrm{R} \$ 150,92$ do Budget e o lucro somado ao que não foi utilizado foi de $\mathrm{R} \$ 2.985,84$.

\begin{tabular}{ccccccc}
\hline Mês & Conversão & Gasto & Ganhos & Lucro & Sobra & Lucro+Sobra \\
\hline 1 & 36 & 800,73 & 1008,00 & 207,27 & $-0,73$ & 206,54 \\
2 & 43 & 756,58 & 1204,00 & 447,42 & 43,42 & 490,84 \\
3 & 37 & 738,71 & 1036,00 & 297,29 & 61,29 & 358,58 \\
4 & 37 & 771,31 & 1036,00 & 264,69 & 28,69 & 293,38 \\
5 & 44 & 797,27 & 1232,00 & 434,73 & 2,73 & 437,46 \\
6 & 47 & 797,88 & 1316,00 & 518,12 & 2,12 & 520,24 \\
7 & 41 & 792,72 & 1148,00 & 355,28 & 7,28 & 362,56 \\
8 & 34 & 796,00 & 952,00 & 156,00 & 4,00 & 160,00 \\
9 & 34 & 797,88 & 952,00 & 154,12 & 2,12 & 156,24 \\
\hline Total & 353 & 7049,08 & 9884 & 2834,92 & 150,92 & 2985,84 \\
\hline
\end{tabular}

Tabela 5.4: Demostrativo da Campanha Utilizando Método Tradicional

A campanha tradicional obteve mais conversões do que a utilizando Teoria da Decisão, entretanto obteve um lucro menor gastando quase que integramente o Budget disponível. 
Então obtivemos um lucro maior mesmo gastando menos e com uma menor quantidade de conversão, o que comprova que nem sempre investir mais dinheiro vai aumentar o retorno final.

Quando se analisa o lucro mês a mês, pode-se ter a impressão que os valores do lucro são similares conforme mostra a Figura 5.4 que apresenta o Boxplot do lucro utilizando-se a Teoria da Decisão e o método tradicional, entretanto quando soma-se o que não foi investido na campanha há uma diferença gritante conforme pode ser visualizado no Boxplot da Figura 5.5 .

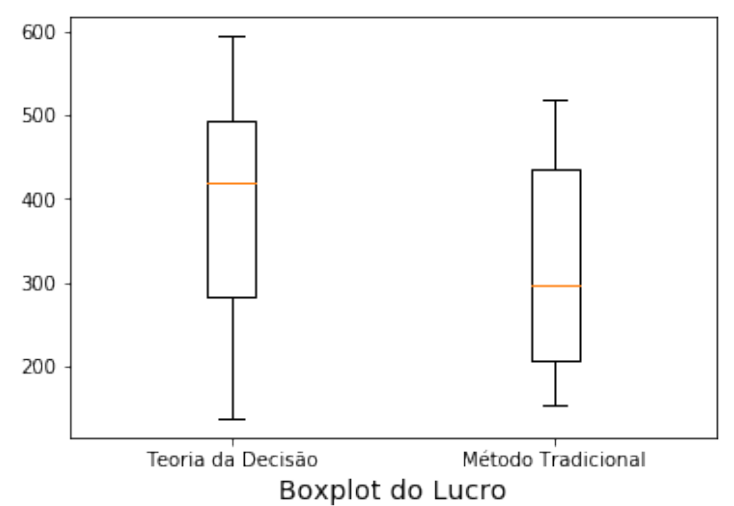

Figura 5.4: Boxplot do Lucro das Campanhas

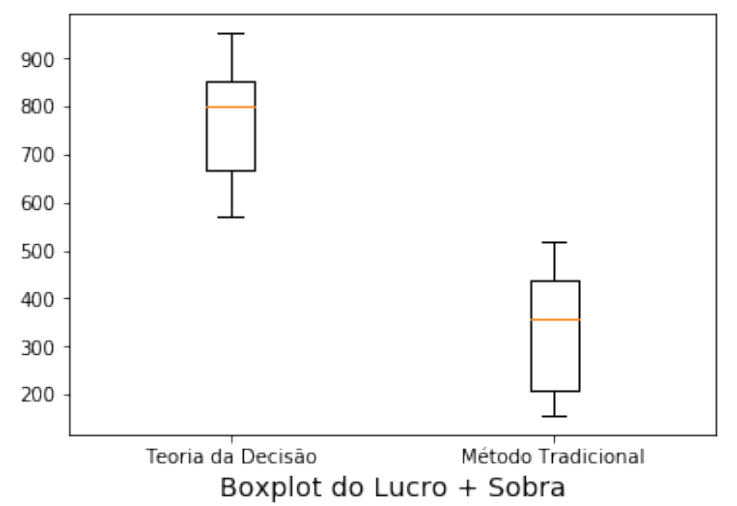

Figura 5.5: Boxplot do Lucro mais Sobra das Campanhas

Para fazer a comparação utilizando-se as métricas que geralmente são utilizadas para avaliar campanhas no marketing digital, vamos comparar o $C P A$ e o $R O A S$ entre as duas metodologias. A Tabela 5.3 apresenta o comparativo entre o $R O A S$ e o $C P A$ das duas metodologia, analisando-se as duas métricas o método proposto foi superior em ambas pois apresenta um ROAS de 0,91 conta 0,41 e um CPA de $\mathrm{R} \$ 14,64$ contra $\mathrm{R} \$ 19,97$.

\begin{tabular}{lll}
\hline Metodologia & ROAS & CPA \\
\hline Teoria da Decisão & 0,91 & $\mathrm{R} \$ 14,64$ \\
Método Tradicional & 0,40 & $\mathrm{R} \$ 19,97$ \\
\hline
\end{tabular}

Tabela 5.5: Comparativo do ROAS e CPA entre a metodologia proposta e a tradicional

Uma ultima consideração importante é que a metodologia tradicional simulada neste trabalho é utilizada pela maiorias das empresas que anunciam no Google, na qual o anunciante apenas aceita deixar o $C P C M$ proposto pelo Google Ads. 


\section{Capítulo 6}

\section{Conclusão}

Este trabalho apresentou um método de otimização para campanhas no Google Ads utilizando Teoria da Decisão Bayesiana, o qual fornece uma solução alternativa para um problema dentro da área de publicidade digital, onde devido a grande dimensionalidade das variáveis (quantidade de configurações) é difícil analisar e obter uma campanha otimizada em todo seu espaço de decisões. Neste sentido, o método desenvolvido contempla essa situação.

\section{Recomendações para Trabalhos Futuros}

- Fazer um planejamento de uma campanha para aplicar a metodologia proposta neste trabalho.

- Análise multivariada para agrupar configurações similares e diminuir a dimensionalidade do modelo proposto.

- Estudo de modelos que melhor estimem o $C T R$ e o $C P C$ para cada configuração, levando-se em conta que é necessário percorrer o espaço de decisão do $C P C M$.

- Construção de um modelo utilizando algoritmo EM para avaliar campanhas que não percorrem todo o espaço de decisão do $C P C M$.

- Ampliar a metodologia proposta utilizando modelo de espaço temporal para modelar a quantidade de buscas sazonais por local.

- Ampliar a metodologia proposta utilizando Teoria da Decisão para analizar a correspondência de palavras-chave. Para maiores detalhes sobre tipos de correpondência de 
palavras-chave ver em GOOGLE (d).

- Otimização de campanhas do Google Ads para o Google Shopping.

- Otimização de campanhas para rede de display.

- Otimização de campanhas de Remarketing no Google Ads.

- Otimização de campanhas do Facebook Ads.

- Ampliar está pesquisa para otimização de publicidades multi-canais e multi plataformas com uma verba de marketing (Budget) restrita. 


\section{Apêndice A}

\section{Classes com priores Conjugadas}

Há casos nos quais as distribuições a priori e a posteriori pertencem à mesma família de distribuição o que facilita bastante nos cálculos e na interpretação. Quando isto ocorre chamamos essa família de distribuições conjugadas. Este resume apresenta algumas conjugações, entretanto não focaremos nas demostrações das mesma (leitor pode consultar por exemplo, DeGroot (1970) ou Louzada (2014)).

\section{A.1 Priori Beta e amostras de Bernoullis}

Suponha que $X_{1}, X_{2}, \ldots, X_{n}$, dado, $\theta$ são condicionalmente independentes e identicamente distribuídas (ciid) segundo o modelo de $\operatorname{Ber}(\theta)$ e que a distribuição a priori para $\theta$ é uma $\operatorname{Bet} a(a, b), a, b>0$. Então:

$$
\theta \mid X_{1}=x_{1}, \ldots, X_{n}=x_{n} \sim \operatorname{Bet} a\left(a+\sum_{i=1}^{n} x_{i}, b+n-\sum_{i=1}^{n} x_{i}\right)
$$

\section{A.2 Priori Gama e amostras de Poisson}

Suponha que $X_{1}, X_{2}, \ldots, X_{n}$ dado, $\theta$ são condicionalmente independentes e identicamente distribuídas (ciid) segundo o modelo de $P(\theta)$ e que a distribuição a priori para $\theta$ é uma $\operatorname{Gama}(a, b), a, b>0$. Então:

$$
\theta \mid X_{1}=x_{1}, \ldots, X_{n}=x_{n} \sim \operatorname{Gama}\left(a+\sum_{i=1}^{n} x_{i}, b+n\right)
$$

\section{A.3 Priori Pareto e amostras de Uniforme}

Suponha que $X_{1}, X_{2}, \ldots, X_{n}$ dado, $\theta$ são condicionalmente independentes e identicamente distribuídas (ciid) segundo o modelo de $U(0, \theta)$ e que a distribuição a priori para $\theta$ é uma Pareto $(a, b), a, b>0$. Isto é: 


$$
f(\theta)=a b^{a} \frac{1}{\theta^{\alpha+1}} \mathbb{I}_{(b, \infty)}(\theta)
$$

então:

$$
\theta \mid X_{1}=x_{1}, \ldots, X_{n}=x_{n} \sim \operatorname{Pareto}\left(a+n, \max \left(b, x_{(n)}\right)\right)
$$

\section{A.4 Priori Gama e amostras de Exponencial}

Suponha que $X_{1}, X_{2}, \ldots, X_{n}$ dado, $\theta$ são condicionalmente independentes e identicamente distribuídas (ciid) segundo o modelo de $\operatorname{Exp}(\theta)$ e que a distribuição a priori para $\theta$ é uma Pareto $(a, b), a, b>0$. Então:

$$
\theta \mid X_{1}=x_{1}, \ldots, X_{n}=x_{n} \sim \operatorname{Gama}\left(a+n, b+\sum_{i=1}^{n} x_{i}\right)
$$

\section{A.5 Prioris Normais e Gama com amostras Normais}

Suponha que $X_{1}, X_{2}, \ldots, X_{n}$ dado $\theta=\left(\theta_{1}, \theta_{2}\right)$ são condicionalmente independentes (ciid) segundo o modelo de $N\left(\theta_{1}, \theta_{2}^{-1}\right)$, com $\theta_{1} \in \mathbb{R}, \theta_{2}>0$ e que a distribuição a priori para $\theta_{2}$ é uma $\operatorname{Gama}(a, b), a, b>0$ e que $\theta_{1} \mid \theta_{2} \sim N\left(c, d \theta_{2}^{-1}\right), c \in \mathbb{R}, d>0$. Então:

$$
\theta_{2} \mid X_{1}=x_{1}, \ldots, X_{n}=x_{n} \sim \operatorname{Gama}\left(a+\frac{n}{2}, b+\frac{1}{2} \sum_{i=1}^{n}\left(x_{i}-\bar{X}\right)^{2}+\frac{n(\bar{X}-c)^{2}}{2(n d+1)}\right)
$$

$\mathrm{e}$

$$
\theta_{1} \mid \theta_{2}, X_{1}=x_{1}, \ldots, X_{n}=x_{n} \sim N\left(\frac{n d \bar{x}+c}{n d+1}, \frac{d}{(n d+a) \theta_{2}}\right)
$$

\section{A.6 Prioris Dirichilet com amostras Multinomiais}

Suponha que $X_{1}, X_{2}, \ldots, X_{p}$ dado, $\theta=\left(\theta_{1}, \ldots, \theta_{p}\right)$ são condicionalmente independentes e identicamente distribuídas (ciid) segundo o modelo $\operatorname{Multinomial}(\theta)$ e que a distribuição a priori para $\theta \sim \operatorname{Dirichlet}(a)$, onde $a=\left(a_{1}, \ldots, a_{p}\right)$. Então:

$$
\theta \mid X_{1}, X_{2}, \ldots, X_{p} \sim \operatorname{Dirichlet}\left(a_{1}+x_{1}, \ldots, a_{p}+x_{p}\right) .
$$


Apêndice B

Otimização de MC para Calcula CPCM 
achar_cpcm = def $\left(c p c \_m i n, c p c \_m a x, i q, f, g, n\right):$

\# $c p c_{-}$min é o lance mínimo para estar na primeira página

\# cpc_max é o limite superior para o lance

\# iq é o indice de qualidade

\# f é a função que calcula o budget máximo em função do lance

\# g é a função que calcula o roas esperado em função do lance

\# $n$ será o tamanho do vetor que será utilizado no monte carlo

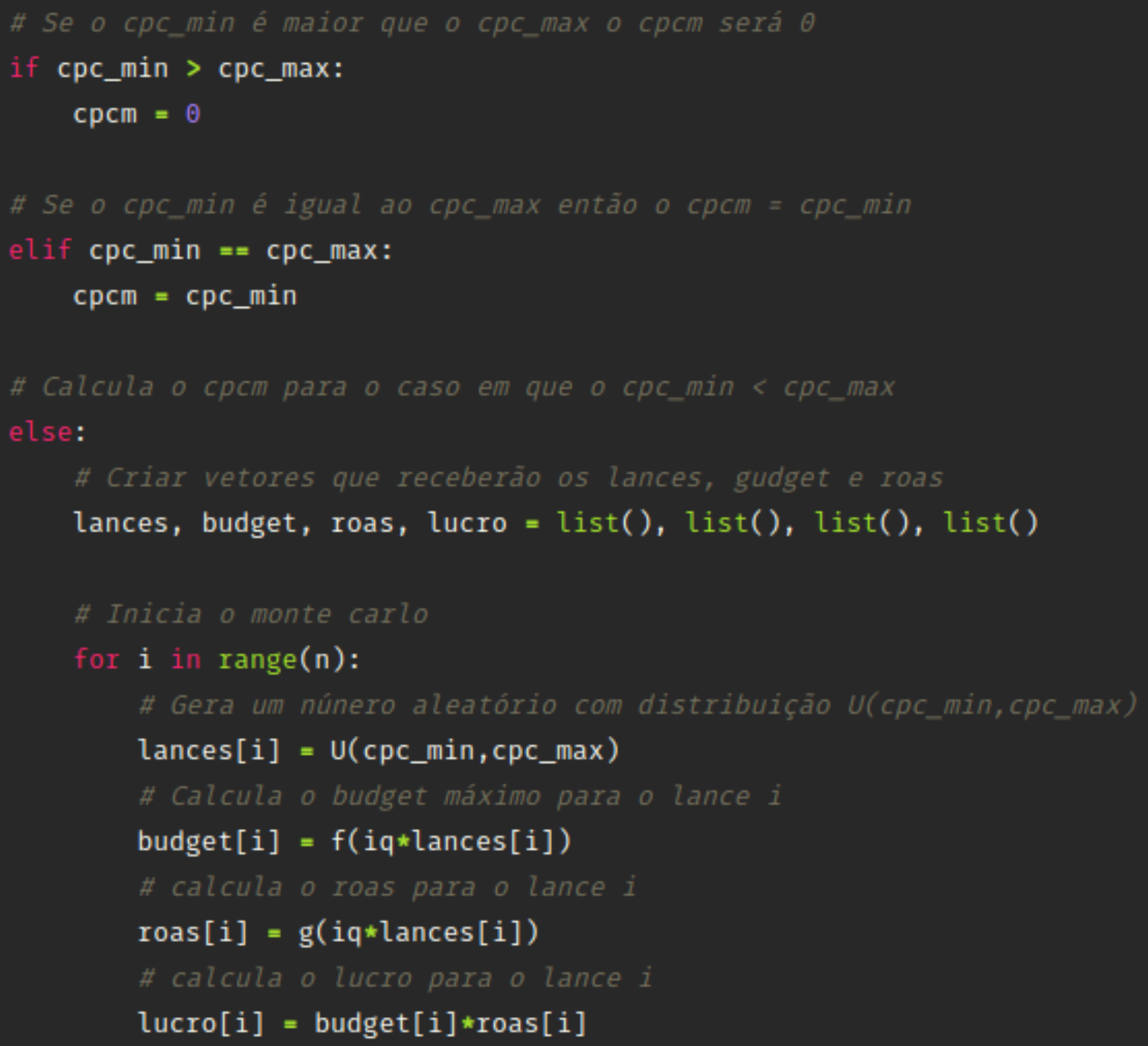

Figura B.1: Lógica do programa 


\section{Referências Bibliográficas}

Adolpho(2016) Conrado Adolpho. Os 8 Ps do Marketing Digital. Novatec. Citado na pág. 4, 5,7

DeGroot(1970) Morris H DeGroot. Optimal Statistical Decisions. Citado na pág. 21, 24, 25, 26,65

Duijndam(2011) Kevin Duijndam. Adwords bid optimisation. Dissertação de Mestrado, VU UNIVERSITY AMSTERDAM. Citado na pág. 1

GOOGLE(a) GOOGLE. Google ads, a. URL https://ads.google.com/. Citado na pág. 10

GOOGLE(b) GOOGLE. Retorno do investimento (roi) - ajuda do google ads, b. URL https://support.google.com/google-ads/answer/14090. Citado na pág. 8

GOOGLE(c) GOOGLE. Sobre o Índice de qualidade - ajuda do google ads, c. URL https://support.google.com/google-ads/answer/7050591. Citado na pág. 12

GOOGLE(d) GOOGLE. Sobre opções de correspondência de palavra-chave, d. URL https://support.google.com/google-ads/answer/7478529. Citado na pág. 64

Graepel et al.(2010) Thore Graepel, Joaquin Quinonero Candela, Thomas Bochert, Ralf Herbrich e Rherb Microsoft Com. Web-Scale Bayesian Click-Through Rate Prediction for Sonsored Search Advertising in Microsofts's Bing Search Engine. Em ICML. ISBN 9781605589077. doi: 10.1016/j.bbr.2012.06.005. Citado na pág. 1

Halligan et al.(2009) Brian Halligan, Dharmesh Shah e David Meerman Scott. Inbound marketing : Get found using google, social media, and blogs. Em Inbound marketing : get found using Google, social media, and blogs. ISBN 978-0470499313. doi: 10.1007/ s13398-014-0173-7.2. Citado na pág. 5

Inoue(2009) Giovanni Parmigiani Lurdes Inoue. Decision Theory: Principles and Approaches. Wiley. Citado na pág. 25, 26

Kim et al.(2006) Hoon Kim, Christian P. Robert e George Casella. Monte Carlo Statistical Methods. Technometrics. ISSN 00401706. doi: 10.2307/1270959. Citado na pág. 27, 28 
KOTLER(2017) HERMAWAN KARTAJAYA IWAN SETIAWAN PHILIP KOTLER. MARKETING 4.0 Moving from Traditional to Digital. John Wiley \& Sons. Citado na pág. 3,4

Levin(2004) Roger Levin. Return on investment, 2004. ISSN 00028177. Citado na pág. 8

Lindley(1991) Dennis Victor Lindley. Making Decisions - Second Edition. John Wiley \& Sons. Citado na pág. 19

Lindley(2006) Dennis Victor Lindley. Understanding Uncertainty. Wiley-Interscience. Citado na pág. 19

Louzada(2014) Helio S. Migon Dani Gamerman Francisco Louzada. Statistical Inference: An Integrated Approach. CHAPMAN \& HALL. Citado na pág. 27, 65

Muthukrishnan et al.(2010) S. Muthukrishnan, Martin Pal e Zoya Svitkina. Stochastic models for budget optimization in search-based advertising. Em Algorithmica (New York). ISBN 0178-4617. doi: 10.1007/s00453-009-9311-6. Citado na pág. 1

Patrutiu Baltes(2016) Loredana Patrutiu Baltes. Inbound Marketing - the most important digital marketing strategy. Bulletin of the Transilvania University of Brasov. Series V: Economic Sciences. ISSN 20652194. doi: 10.1016/j.ijhydene.2016.08.062. Citado na pág. 5 